\title{
LOS ALUDES DE NIEVE \\ EN EL MACIZO DE PEÑALARA
}

Nota técnica 14 de AEMET

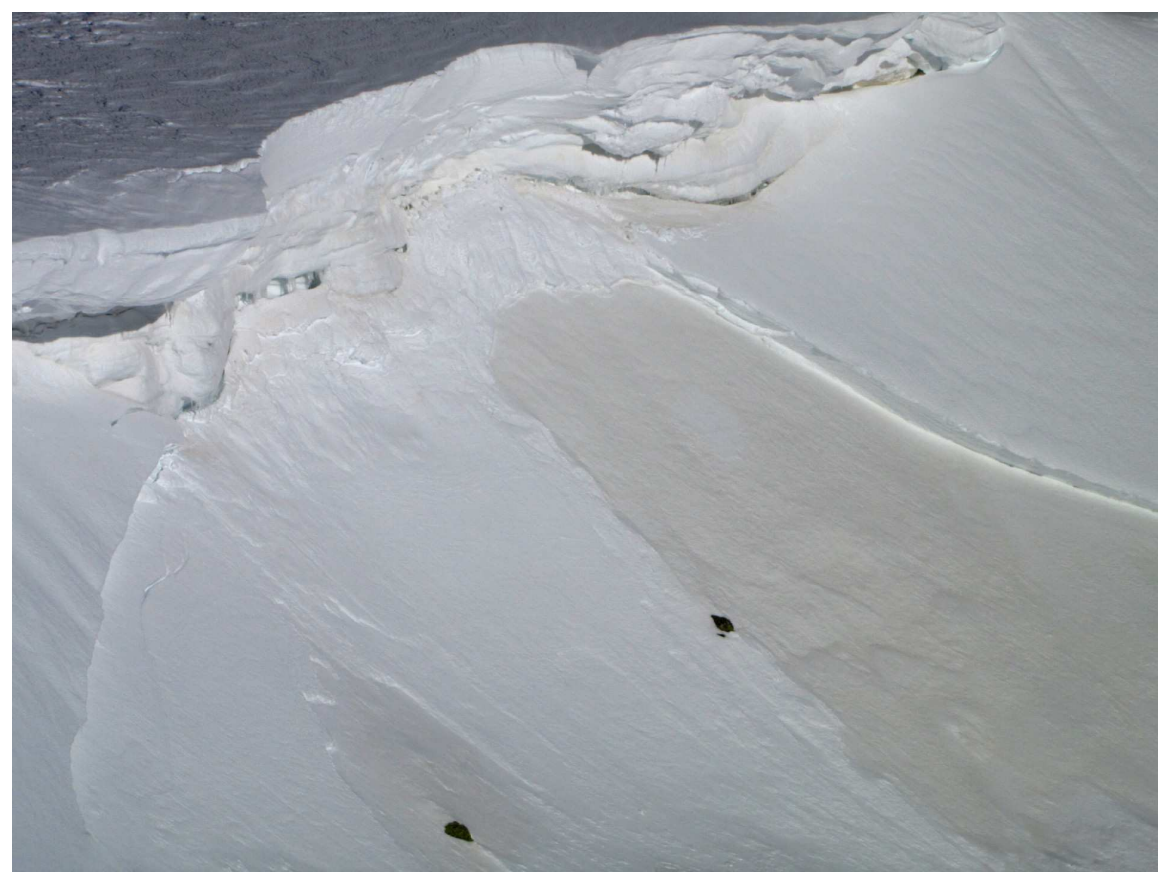

Juan Antonio Fernández-Cañadas López-Peláez

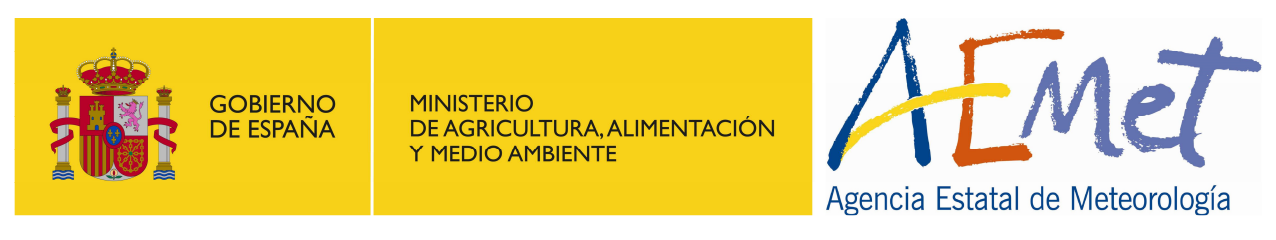


Este trabajo se realizó en el contexto de un convenio de colaboración entre la UNED y la $A E M E T$, siendo el tutor del mismo por parte de la UNED David Cocero Matesanz y Luis Pantoja Trigueros por parte de AEMET.

\section{datos \\ abiertos}

Aviso Legal: los contenidos de esta publicación podrán ser reutilizados, citando la fuente y la fecha, en su caso, de la última actualización

\section{Edita:}

(C) Ministerio de Agricultura, Alimentación y Medio Ambiente Agencia Estatal de Meteorología Madrid, 2014

Catálogo de Publicaciones de la Administración General del Estado: https://cpage.mpr.gob.es

NIPO: 281-14-005-3

https://doi.org/10.31978/281-14-005-3

Agencia Estatal de Meteorología (AEMET)

C/ Leonardo Prieto Castro, 8

28040 Madrid

http://www.aemet.es/

@Aemet_Esp

https://www.facebook.com/AgenciaEstataldeMeteorologia 


\section{LOS ALUDES DE NIEVE EN EL MACIZO DE PEÑALARA}

Nota técnica 14 de AEMET

Juan Antonio Fernández-Cañadas López-Peláez 
INDICE

1. INTRODUCCIÓN

2. LOS ALUDES

3. HIPOTESIS Y OBJETIVOS

4. AREA DE ESTUDIO

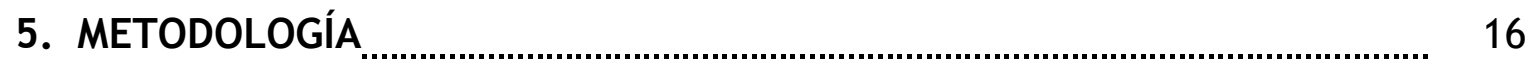

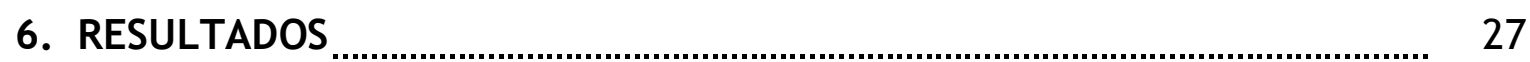

6.1. Aludes observados _................................................................. 27

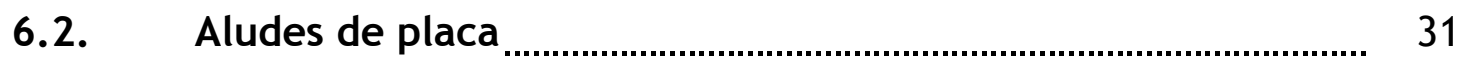

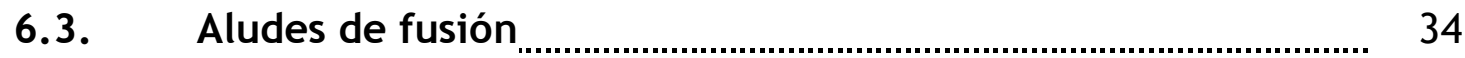

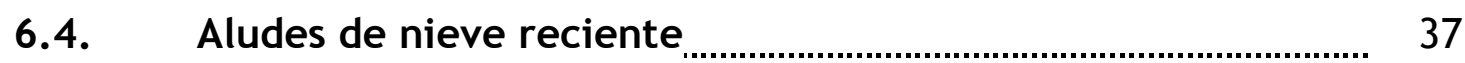

6.5. Cartografía general de riesgo de aludes ....................................... 40

7. CONCLUSIONES

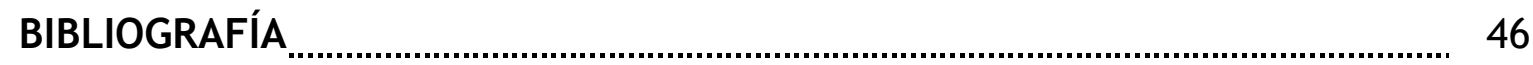

ANEXO I. CARTOGRAFÍA _.............................................................................. 50

ANEXO II. ÍNDICE DE FIGURAS _...................................................................... 57 


\section{1.- INTRODUCCIÓN.}

Las zonas de montaña presentan una exposición especial a ciertos riesgos naturales. La ordenación y gestión del territorio, la construcción de infraestructuras y la planificación de actividades en áreas de montaña exigen del conocimiento de los factores que generan estos riesgos, así como de la utilización de una cartografía en la que aparezcan las zonas expuestas a ellos.

Desde mediados del siglo XX, la generalización de los deportes de invierno en sus distintas modalidades ha hecho que algunas zonas de montaña hayan experimentado una transformación de su uso tradicional agrario y forestal a un uso turístico. Este cambio de uso de suelo ha originado la construcción de distintos tipos de infraestructuras en estos espacios, como estaciones de esquí, refugios de montaña, hoteles, urbanizaciones y carreteras.

El desencadenamiento de aludes es uno de los peligros más frecuentes en zonas de montaña. A pesar de que nuestro país no presenta, en general, un riesgo elevado de desencadenamiento de aludes, el número de víctimas por ellos se ha ido incrementando en las últimas décadas.

Todos estos hechos hacen que el estudio y análisis de la dinámica de aludes, tanto en su vertiente espacial como temporal, presente cada vez mayor interés, y que, en los últimos años, se hayan elaborado distintos estudios sobre la incidencia de este proceso en áreas concretas y sobre los aspectos teóricos de su dinámica.

\section{2.- LOS ALUDES.}

Las áreas de alta montaña son proclives al desencadenamiento de distintos procesos geomorfológicos de carácter violento entre los que se encuentra el desencadenamiento de aludes de nieve. Este hecho ha propiciado la proliferación de estudios y el desarrollo de metodologías diversas orientadas a la delimitación de áreas favorables a estos desencadenamientos.

En Europa la elaboración de cartografías de aludes está atribuida, en general, a los organismos con competencias en la Ordenación del Territorio.

En España existen distintos organismos que se han ocupado de la delimitación de áreas favorables al desencadenamiento de aludes. En Cataluña, el Institut Geològic de Catalunya y la Facultad de Geología de la Universidad de Barcelona han elaborado cartografías de este fenómeno en el Pirineo catalán y se han realizados trabajos de investigación relativos a estos procesos (Furdada, 1996).

En el Pirineo aragonés, la cartografía de zonas probables de desencadenamiento de aludes ha estado desarrollada por el Instituto Geológico y Minero de España que, desde 1990, ha tratado de desarrollar la cartografía a partir de trabajos previos de los Servicios Forestales del Estado en los 
valles del Aragón y del Gállego (Muñoz, 1988; Saez Alagón, 1993 y 1995). El Departamento de Geografía y Ordenación del Terrritorio de la Universidad de Zaragoza también ha realizado distintos trabajos acerca de la delimitación de zonas probables de aludes en distintas zonas del Pirineo Aragonés como el Valle de Ordesa, (Julián et al., 2000; Julián y Chueca, 1999), el alto Gállego, (Julián y Chueca, 2010), y en el circo de Piedrafita (Palomo, 2007; Palomo et al., 2008).

Fuera del ámbito geográfico de la Cordillera Pirenaica, en la Cordillera Cantábrica el Instituto de Recursos Naturales y Ordenación del Territorio de la Universidad de Oviedo elaboró un estudio que incluye un mapa de susceptibilidad por aludes de nieve en Asturias, y una evaluación y cartografía del riesgo de aludes en el camino de acceso a la Vega de Urriellu en los Picos de Europa (Vada et al., 2012); también se puede destacar una cartografía de zonas de aludes en el Alto Sil (Santos et al., 2010).

Un alud es un desplazamiento rápido de una masa de nieve por la ladera de una montaña. Cuando el volumen de nieve que se pone en movimiento es pequeño y el recorrido de la nieve no es muy extenso se denominan coladas.

La probabilidad de que en un área se desencadene un alud en un momento dado depende de dos tipos de variables:

- Variables meteorológicas y nivológicas como la precipitación, la temperatura, el viento y el estado y evolución del manto nivoso. Estas variables son independientes del terreno y sufren importantes variaciones temporales.

- Variables relacionadas con el terreno, permanentes y susceptibles de ser cartografiadas. La mayor parte de los autores coinciden en señalar que las variables más importantes a considerar son la altitud, la pendiente, la morfología y la rugosidad del terreno, la vegetación existente, y la orientación.

Existen numerosas clasificaciones de aludes en función de diversos criterios. Según el contenido de agua líquida que contiene la nieve movilizada, los aludes se pueden clasificar como aludes de nieve seca o de nieve húmeda. Otro de los criterios de clasificación atiende a características morfológicas, clasificándolos según el tipo de salida, que puede ser lineal o puntual, según el espesor del manto que se pone en movimiento (aludes de superficie cuando solo se desplaza la parte superior del manto, y aludes de fondo cuando se desplaza todo el conjunto del manto, desde la superficie hasta el suelo). Otras clasificaciones están basadas en la capacidad destructiva de las avalanchas. 
La Comisión Internacional de Nieve y Hielo (UNESCO) estableció en 1981, una propuesta de clasificación de los aludes según sus aspectos morfológicos y sus factores genéticos. Esta clasificación tiene en cuenta el volumen y las características de la salida, del trayecto y de la zona de llegada (Rey, 1985).

Esta clasificación fue adaptada y posteriormente mejorada por el CEMAGREF/CEN, organismo francés vinculado al Ministerio de Agricultura, que en Francia tiene las competencias en la elaboración de mapas de riesgo de aludes.

En este trabajo se utilizará la clasificación utilizada por AEMET basada en factores genéticos, según la cual los aludes se clasifican en:

- Aludes de placa.

- Aludes de nieve reciente.

- Aludes de fusión o de nieve húmeda.

Los aludes de placa se caracterizan porque la nieve que forma la placa suele ser compacta (placa dura), seca y de una densidad bastante elevada. En ocasiones la placa puede presentar una débil cohesión (placa friable) o la nieve ser húmeda (placa húmeda). Presentan una salida lineal, con una cicatriz muy clara que puede propagarse rápidamente gracias a la cohesión de la nieve. La fractura puede llegar a ser larga y depende de la topografía del terreno. Los aludes de placa causan el $80 \%$ de los accidentes por alud (Guyomarc'h, 1996).

Los aludes de fusión o aludes de nieve húmeda se desencadenan sobre mantos de nieve compuestos por nieve con un alto contenido en agua líquida. La salida puede ser lineal o puntual en función de la cohesión de la nieve. La elevada densidad de la nieve que se pone en movimiento hace que este tipo de aludes se puedan producir a partir de pendientes relativamente bajas, en torno a $25^{\circ}$. Suelen seguir recorridos bien localizados y conocidos. Son los aludes que más erosión causan. (Guyomarc'h, 1996).

Los aludes de nieve reciente se caracterizan por que la nieve que se pone en movimiento suele ser seca y fría y presenta una cohesión muy débil. La salida suele ser puntual. Se suelen desencadenar durante o poco después de las nevadas. (Guyomarc’h, 1996).

\section{3.- HIPOTESIS Y OBJETIVOS.}

Este artículo resume un estudio empírico sobre avalanchas en el macizo de Peñalara y compara los resultados relativos a su distribución con los obtenidos mediante la aplicación de dos modelos de 
clasificación del terreno. El primer modelo, que es el propuesto por el autor, introduce variables típicas en este tipo de estudios, como la pendiente y la presencia de bosques densos, y otras, específicamente relevantes para esta zona, como las zonas de acumulación de nieve, orientaciones favorables a la formación de placas e insolación potencial. La salida final de este modelo son unos mapas en los que se expone, en formato raster, las zonas probables al desencadenamiento de aludes. El otro modelo está basado en la Escala de Terrenos Expuestos a Avalanchas (Avalanche Terrain Exposure Scale, ATES), ha sido propuesto por el Centro de Avalanchas de Canadá, y combina datos geomorfológicos y nivológicos con criterios derivados del conocimiento empírico del terreno. La salida final de este segundo modelo es un mapa vectorial que muestra la clasificación del terreno en función de su exposición a los aludes.

El estudio empírico analiza el tipo y frecuencia de los aludes observados, las zonas en las que suelen producirse y las condiciones meteorológicas y nivológicas que propician su desencadenamiento.

El objetivo final del artículo es ajustar la clasificación de los terrenos del Macizo de Peñalara que resultan de la aplicación de la clasificación del Centro de Avalanchas de Canadá mediante los resultados del modelo propuesto por el autor y comparar el resultado con los datos del estudio empírico. Así mismo, realizar una primera aproximación a la elaboración de una cartografía en la que queden reflejadas las áreas favorables al desencadenamiento de aludes en este espacio.

\section{4.- AREA DE ESTUDIO.}

El Macizo de Peñalara forma parte de la Sierra de Guadarrama que, a su vez, constituye una de las unidades que componen el Sistema Central. La línea de cumbres de esta cadena constituye, en muchos tramos, el límite entre las comunidades autónomas de Madrid y de Castilla y León (figura 1). 


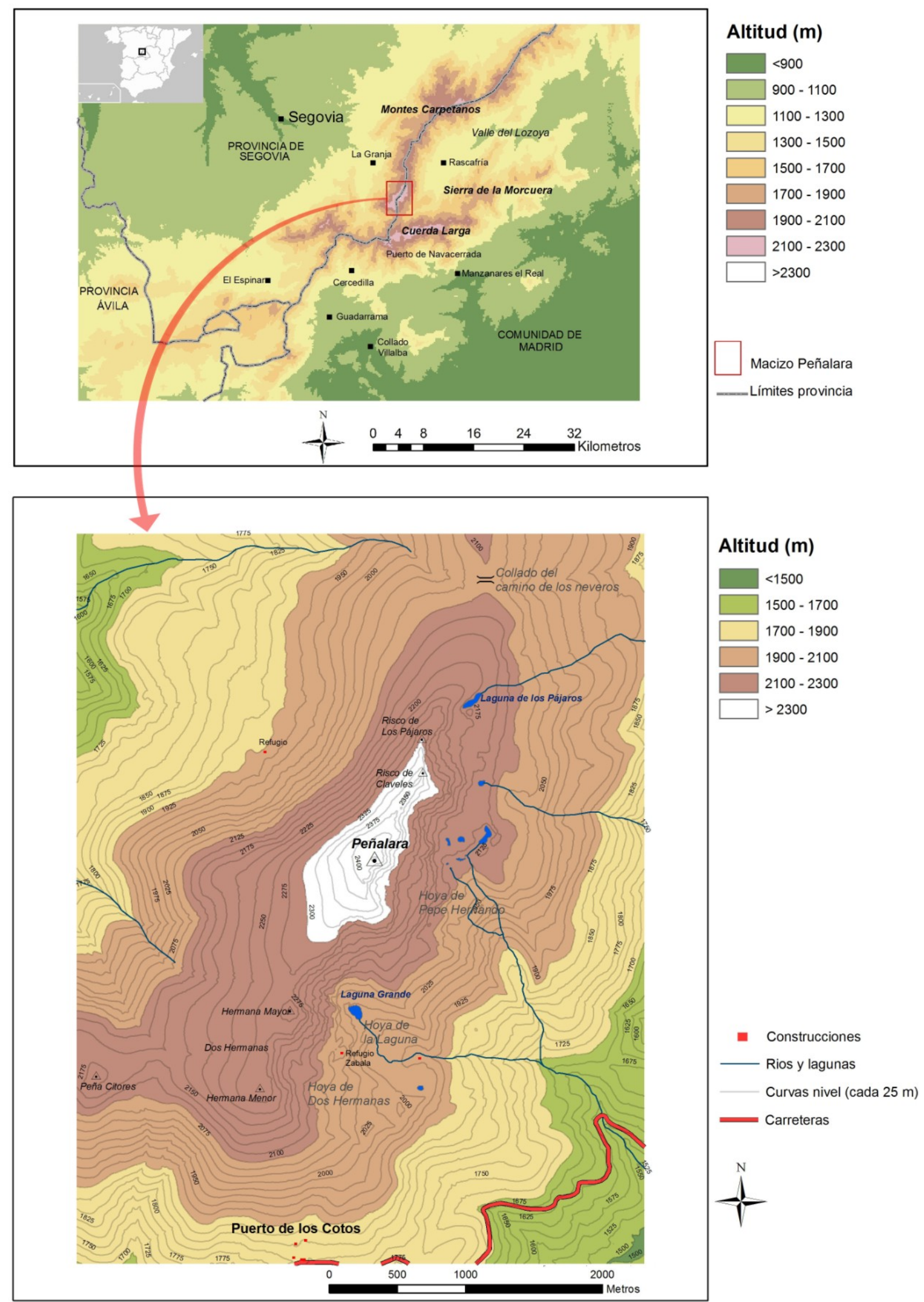

Figura 1: Mapa de situación del Macizo de Peñalara. Elaboración propia. 
El Parque Natural de la Cumbre, Circo y Lagunas de Peñalara, con 714 hectáreas, fue declarado en la Ley 6/1990 y forma parte de la red de Espacios Naturales Protegidos de la Comunidad de Madrid. Con esta declaración se reclasificaba la figura de protección original de 1930, que era la de Sitio Natural de Interés Nacional. El Parque Natural de Peñalara tiene por objetivo la conservación de los ecosistemas más representativos de la alta montaña de la región, ya que en él se encuentra la cima más elevada de la provincia (Pico Peñalara, $2.428 \mathrm{~m}$ ).

El Macizo de Peñalara está incluido en el Parque Nacional de la Sierra de Guadarrama declarado por Ley el 13 de junio de 2013. El Parque Nacional tiene una superficie de 33.960 hectáreas, repartidas entre las Comunidades Autónomas de Madrid (21.714) y Castilla y León (12.246).

La proximidad de este espacio a la ciudad de Madrid y su accesibilidad da lugar a que la afluencia de deportistas, esquiadores, senderistas y montañeros haya ido aumentando. Como consecuencia, también se ha incrementado el número de accidentes registrados provocados por el desencadenamiento de distintos procesos naturales como los aludes.

Existen numerosos estudios que describen los aspectos geomorfológicos del Macizo de Peñalara. Obermaier y Carandell, en 1917, fueron los primeros en describir las morfologías glaciares existentes en la Sierra de Guadarrama; Franzle, en 1959; Bullón (1988), Sanz (1988), Pedraza et al. (2004), Asensio y Ontañón (1972 y 1975), Bullón (1977, 1988 y 1995), Sanz (1979, 1986 y 1988), Palacios y García (1997a), Marcos y Palacios (2004), Muñoz y García (2004), Palacios y Andrés (2000) y Palacios et al. (2003 y 2004) se han ocupado de los procesos geomorfológicos que tienen lugar en la actualidad; Bullón (1995), Muñoz et al. (1995), Palacios y García (1997a), Palacios y García (1997b), Palacios y Andrés (2000), Palacios et al., (2003 y 2004), Marcos y Palacios (2004), Muñoz y García (2004), Andrés y Palacios (2004 y 2005), Andrés et al., (2007) y Palomo (2012) han estudiado la relación entre diversos agentes geoecológicos que actúan en el macizo, haciendo especial hincapié en la relación entre geomorfología, nieve y vegetación, y otros autores (Rivas-Martínez, 1963 y 1982; Sanz, 1979 y 1988; Bullón, 1988; Fernández-González, 1988, 1991 y 1999; RivasMartínez et al., 1990 y 1999; Luceño y Vargas, 1991; Gavilán et al., 1998; Andrés y Palacios, 2004; Muñoz y García, 2004; Palacios et al., 2003 y 2004), se han ocupado de la descripción del Macizo en relación con su vegetación y la evolución de ésta. Todos estos trabajos han permitido alcanzar un conocimiento exhaustivo del Macizo de Peñalara en sus distintos aspectos geográficos.

De todos estos trabajos se puede concluir que el Macizo de Peñalara constituye un ejemplo significativo de territorio cuyo relieve es el resultado de la acción de distintos procesos de tipo estructural y climático. A finales del Pleistoceno este territorio se vio afectado por una acción 
glaciar marginal. Los hielos cubrieron esta zona alcanzando un espesor de hasta 300 metros en algunos puntos, una longitud máxima de 1,65 $\mathrm{km}$ y cubrieron el suelo de zonas situadas a una altitud mínima estimada de $1.840 \mathrm{~m}$ en el glaciar de Peñalara. Posteriormente, el retroceso de estos glaciares dejó como resultado un conjunto de morfologías glaciares bien conservadas. (Palacios et al., 2006).

A finales del Paleozoico esta zona fue una penillanura de materiales gneísecos sobre la que actuaron los movimientos tectónicos del Terciario para generar un relieve de bloques elevados y hundidos (horst y graben) que separan ambas mesetas, constituidos básicamente por gneises glandulares con intrusiones graníticas, ofreciendo un perfil en general suave. Dicha suavidad se rompe donde los glaciares dejaron su huella en forma de circos (hoyas).

En épocas preglaciares el Macizo estuvo afectado por pulsaciones frías y secas que provocaron, entre otras cosas, la formación de campos de bloques por procesos de macrogelifracción de la roca (Sanz, 1986) y la aparición de un manto de alteración de materiales finos. Estas formaciones (manto de alteración y campos de bloques) perduran en la actualidad sobre todo en las vertientes occidentales del macizo (Palacios et al., 2006).

A finales del Pleistoceno, el descenso de las temperaturas y la abundancia de precipitaciones sólidas propiciaron la instalación de los glaciares en la sierra (Palacios y Andrés, 2005). Parece ser que entonces la circulación general de la atmósfera fue parecida a la actual, pero con una posición más meridional del frente polar, lo que implica que, en el Sistema Central, las precipitaciones fueron más abundantes y las temperaturas más bajas (Palacios et al., 2006). La nieve tendía a acumularse de manera similar a como lo hace en la actualidad, pero los volúmenes de nieve eran significativamente mayores y no llegaba a fundirse en verano, sino que se iba acumulando y transformando en hielo glaciar. Estas masas de hielo glaciar se fueron deslizando debido a su plasticidad, barriendo el manto de alteración original y acumulándolo en grandes morrenas frontales. Al irse desplazando el manto de alteración se fueron excavando los circos glaciares (Palacios et al., 2006).

De esta forma, la distribución de los glaciares en el Macizo presentó una acusada asimetría. Los glaciares más activos se encontraban en las laderas con orientación este, protegidos de los vientos dominantes y de la máxima radiación solar, y las laderas occidentales se caracterizaban por la escasa acumulación de nieve e hielo. 
La asimetría en la distribución de los glaciares tuvo importantes consecuencias geomorfológicas. En las vertientes orientales, además de provocar la aparición de morfologías como morrenas, circos, depresiones etc., los glaciares barrieron el manto de alteración previo eliminándolo en muchas áreas y reduciéndolo considerablemente en otras. En las laderas orientadas al oeste la presencia glaciar fue menos importante, por lo que el manto de alteración permanece inalterado en la mayor parte de estos sectores (Palacios et al., 2006).

Aunque la acción glaciar fue menos importante en las vertientes occidentales, también se conservan ejemplos de algunos pequeños circos glaciares con varias formaciones morrénicas al noroeste de la cima de Peñalara (Alía et al., 1957). Los relieves glaciares aparecen generalmente en los sectores del Macizo situados en las vertientes orientales de éste que superan los 1.800 metros de altitud. Los circos se encuentran cerrados en su base por varias líneas de morrenas más o menos deformadas y, en los casos en los que los arcos morrénicos presentan una dirección marcada del noroeste al sureste, constituyen barreras topográficas frenando y modificando la trayectoria de los vientos del oeste y del suroeste (Obermaier y Carandell, 1917).

El resultado de esta evolución hace que una de las características principales del Macizo de Peñalara en la actualidad sea su marcada asimetría este - oeste en su aspecto geomorfológico, que se refleja en otras facetas como la distribución y persistencia del manto de nieve o en las relacionadas con la distribución de la vegetación, ya que son todos ellos factores interrelacionados (Palacios et al., 2006).

Después de la retirada de los glaciares el relieve del Macizo ha sufrido ligeros retoques ligados, sobre todo, a una moderada acción periglaciar, a los movimientos en masa que se desarrollan en ambas laderas, a la acción torrencial y a los procesos ligados a la presencia de la nieve. La distribución espacial de estos procesos está condicionada por la disposición y la entidad de los materiales sueltos (manto de alteración y morrenas), por la pendiente y, en el caso de los procesos ligados a la nieve, a la distribución de ésta (Palacios y Andrés, 2000).

Los acción periglaciar se centra en la gelifracción que afecta a las paredes rocosas de las vertientes orientales (Palacios y Andrés, 2000) y a algunos procesos de movilidad superficial (Sanz, 1986).

Los procesos de ladera son frecuentes, de forma que existen en el Macizo numerosos ejemplos de conos de gravedad, lóbulos de solifluxión, coladas de gelifluxión y debris flows.

La acción fluvial se materializa sobre todo en la acción de los torrentes que inciden sus cauces en el manto de alteración alcanzando, en ocasiones, varios metros de profundidad. 
Los procesos ligados a la acción nival son los que tienen una mayor relevancia en la zona de estudio y han dado lugar a la aparición de numerosos nichos de nivación en las áreas en las que la acumulación y la persistencia de la nieve es mayor y que coincide, en general, con las cabeceras de los glaciares pleistocenos (Palacios y Andrés, 2000).

La circulación general de la atmósfera en estas latitudes está dominada por los vientos del oeste o ponientes. El frente polar separa el aire polar del tropical y ocupa una zona donde se forman continuas borrascas y se generan fuertes vientos debido a la gran diferencia de temperaturas entre el aire polar y el tropical (Zuñiga y Crespo del Arco, 2009). El chorro polar tiene dirección oesteeste y tiende a ondularse formando las llamadas ondas de Rossby, lo que se traduce en que los vientos que nos llegan adquieran procedencia desde el noroeste al suroeste. En cualquier caso pueden llegar a la Península Ibérica cargados de humedad del Atlántico provocando precipitaciones en el Sistema Central, muchas de ellas en forma de nieve, dependiendo de la temperatura de la masa de aire y de la altitud. Esto tiene una especial relevancia en la localización de los lugares donde se acumula la nieve. En general, la nieve se acumula a sotavento de los vientos dominantes, en nuestro caso en las laderas orientadas al este, desde el nordeste al sureste.

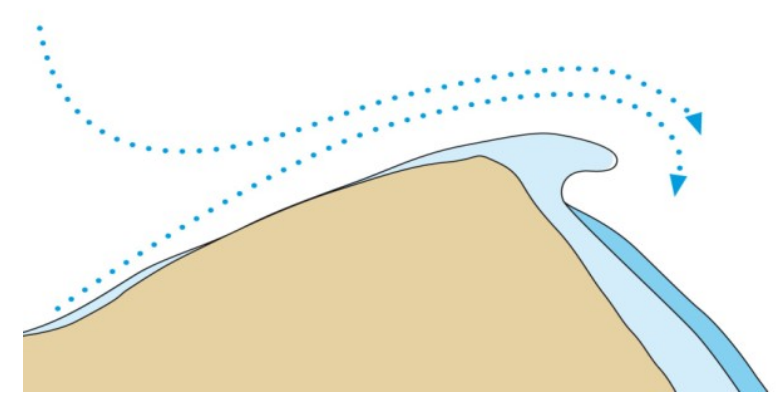

Figura 2: Acumulación de la nieve a sotavento con formación de cornisas y placas de viento. Elaboración propia.

La caracterización climatológica del Macizo de Peñalara puede realizarse a partir de los datos de la serie del observatorio meteorológico del Puerto de Navacerrada, de la Agencia Estatal de Meteorología (AEMET), situado a $1.888 \mathrm{~m}$ de altitud y a unos $5 \mathrm{~km}$ de distancia del Macizo de Peñalara en línea recta. La serie contiene datos desde 1941, aunque no todas las variables se miden desde esa fecha. Algunas de ellas, como el espesor de la nieve, sólo se registran desde 1983.

La nieve es el meteoro más representativo de este macizo montañoso. Las precipitaciones superan los $1.400 \mathrm{l} / \mathrm{m}^{2}$ anuales y se concentran en los meses más fríos, desde octubre a mayo, gran parte de ellas en forma de nieve. El verano es árido. La temperatura media anual en el Puerto de Navacerrada es de $6,1^{\circ} \mathrm{C}$, y la temperatura media mensual es menor de $0^{\circ} \mathrm{C}$ en los meses más fríos (desde diciembre a febrero). Estos datos nos indican que estamos hablando de un clima de alta montaña mediterránea con rasgos continentales (Palacios et al., 2006). 
El manto nivoso se caracteriza por su irregularidad inter e intra anual. De esta manera hay inviernos en los que se producen importantes precipitaciones de nieve que pueden acumular un gran espesor, como el célebre invierno de 1995-1996 en el que la altura de la nieve superó los dos metros en el Puerto de Navacerrada; y otros inviernos con espesores de nieve muy reducidos como el invierno 1994-1995 en el que el espesor máximo en el Puerto de Navacerrada fue tan sólo de $20 \mathrm{~cm}$.

Las nevadas copiosas, como se verá más adelante, son una de las principales causas de los aludes de nieve reciente. Cuando las nevadas copiosas van acompañadas de temperaturas bajas, la nieve puede mantenerse inestable mientras dure el episodio frío y pueden producirse aludes de nieve reciente seca. En el Sistema Central, y en concreto, en el Macizo de Peñalara, las precipitaciones más intensas suelen producirse por advecciones de aire relativamente cálido del tercer cuadrante.

En la tabla de la figura 3 aparecen los días con precipitación, de nieve, aguanieve o lluvia y nieve, igual o superior a $50 \mathrm{l} / \mathrm{m}^{2}$ entre los meses de noviembre a mayo. Se ha incluido la temperatura máxima y mínima registrada, el incremento diario en el espesor de nieve desde el año 1984 y la dirección dominante del viento en superficie, desde 1960, en el observatorio de AEMET del Puerto de Navacerrada. Las temperaturas relativamente suaves, cercanas a los $0^{\circ} \mathrm{C}$, a las que se producen las nevadas provocan que en muchas ocasiones el manto de nieve aumente muy poco su espesor en relación a la cantidad de precipitación registrada, y que la nieve depositada se compacte y estabilice, reduciéndose rápida y notablemente el riesgo de aludes de nieve reciente. 


\begin{tabular}{|c|c|c|c|c|}
\hline FECHA & $\begin{array}{l}\text { PRECIPITACION }\left(1 / \mathrm{m}^{2}\right) \text {, } \\
\text { espesor nieve reciente }\end{array}$ & $\mathrm{T}^{\mathrm{a}} \mathrm{MÁXIMA}\left({ }^{\circ} \mathrm{C}\right)$ & $\mathrm{T}^{\mathrm{a}}$ MÍNIMA $\left({ }^{\circ} \mathrm{C}\right)$ & $\begin{array}{l}\mathrm{T}^{\mathrm{a}} 00 \mathrm{z} 850 \mathrm{hPa} \text {. } \\
\text { DIRECCIÓN VIENTO }\end{array}$ \\
\hline $21 / 10 / 60$ & 105,4 & 5,6 & $-1,4$ & +4. OESTE \\
\hline $29 / 12 / 62$ & 51 & 1,8 & $-0,6$ & +2. OESTE \\
\hline $30 / 12 / 62$ & 56,8 & $-0,8$ & $-3,7$ & $+2 . \mathrm{OESTE}$ \\
\hline $01 / 01 / 63$ & 83,6 & 2,8 & $-2,6$ & +3.SUROESTE \\
\hline $06 / 12 / 63$ & 50,8 & 0,7 & -2 & $+3 . S U R$ \\
\hline $11 / 03 / 64$ & 50,7 & 0,9 & $-2,7$ & +1.SUROESTE \\
\hline $15 / 02 / 66$ & 79,8 & 0,8 & $-1,4$ & +3.SUROESTE \\
\hline $19 / 02 / 66$ & 51,7 & 1 & $-3,2$ & +5.SUROESTE \\
\hline $05 / 11 / 66$ & 91,7 & 1 & $-0,6$ & +1. OESTE \\
\hline $07 / 11 / 66$ & 94,7 & 0,8 & 0,2 & $+4 . S U R$ \\
\hline $08 / 03 / 67$ & 58,1 & 2,4 & 0 & +6.SUROESTE \\
\hline $27 / 11 / 68$ & 74,2 & 5,8 & 0,6 & +10. SUR \\
\hline $18 / 02 / 69$ & 54,1 & 2 & -6 & $0 . S U R$ \\
\hline $21 / 02 / 69$ & 72,2 & 0 & $-2,2$ & +3.SUROESTE \\
\hline $22 / 11 / 69$ & 102,3 & 1,6 & $-0,6$ & +6.SUROESTE \\
\hline $10 / 01 / 70$ & 90,3 & 1 & $-0,2$ & +6.SUROESTE \\
\hline $02 / 12 / 71$ & 50,6 & 0 & $-4,2$ & 0.OESTE \\
\hline $01 / 02 / 72$ & 65 & $-0,6$ & -6 & 0.SUROESTE \\
\hline $02 / 02 / 72$ & 60 & 1,2 & -5 & +1. SUROESTE \\
\hline $05 / 02 / 72$ & 55,2 & 0,6 & $-6,8$ & -1.SUROESTE \\
\hline $04 / 03 / 72$ & 55 & -1 & $-3,2$ & +1. OESTE \\
\hline $14 / 03 / 72$ & 57 & $-0,8$ & $-2,4$ & +1. SUROESTE \\
\hline $03 / 11 / 72$ & 58,6 & 3 & 0,4 & +6. CALMA \\
\hline $19 / 12 / 73$ & 113,7 & 0,4 & $-2,2$ & +4.SUROESTE \\
\hline $15 / 01 / 75$ & 69,6 & 0 & $-1,2$ & +6.SUROESTE \\
\hline $24 / 04 / 75$ & 68,6 & 3,8 & 1 & +7.CALMA \\
\hline $18 / 04 / 76$ & 70,5 & $-0,6$ & $-3,2$ & +3. CALMA \\
\hline $11 / 11 / 76$ & 55,3 & 2,6 & $-3,8$ & +1. OESTE \\
\hline $23 / 02 / 78$ & 74 & 3,6 & 0 & +6.SUROESTE \\
\hline $09 / 11 / 78$ & 106,9 & 3,8 & 1,4 & +3. CALMA \\
\hline $19 / 01 / 79$ & 69,4 & 4 & 0 & +6.SUROESTE \\
\hline $14 / 04 / 80$ & 59 & 2,4 & $-3,4$ & +6.SUROESTE \\
\hline $12 / 05 / 80$ & 67,1 & 7 & $-0,2$ & +7.NOROESTE \\
\hline
\end{tabular}




\begin{tabular}{|c|c|c|c|c|}
\hline FECHA & $\begin{array}{l}\text { PRECIPITACION }\left(\mathrm{l} / \mathrm{m}^{2}\right) \text {, } \\
\text { espesor nieve reciente }\end{array}$ & T $^{\mathrm{a}}$ MÁXIMA $\left({ }^{\circ} \mathrm{C}\right)$ & $\mathrm{T}^{\mathrm{a}}$ MÍNIMA $\left({ }^{\circ} \mathrm{C}\right)$ & $\begin{array}{l}\mathrm{T}^{\mathrm{a}} 00 \mathrm{z} 850 \mathrm{hPa} . \\
\text { DIRECCIÓN VIENTO }\end{array}$ \\
\hline $19 / 12 / 80$ & 98 & 3,2 & $-3,2$ & +1. NOROESTE \\
\hline $08 / 11 / 84$ & $78,1(10 \mathrm{~cm})$ & 2,4 & $-1,4$ & +6.SUROESTE \\
\hline $30 / 11 / 84$ & $58,5((20 \mathrm{~cm})$ & 1 & $-2,8$ & +4.SUROESTE \\
\hline $27 / 12 / 85$ & $56(20 \mathrm{~cm})$ & 0 & $-2,4$ & +1.SUROESTE \\
\hline $16 / 02 / 87$ & $60,5(10 \mathrm{~cm})$ & 2 & $-3,8$ & 0.CALMA \\
\hline $03 / 12 / 87$ & $103,5(10 \mathrm{~cm})$ & 2,4 & $-2,2$ & +4. SUR \\
\hline $18 / 11 / 89$ & $64,9(5 \mathrm{~cm})$ & 0 & $-2,4$ & +5.SUROESTE \\
\hline $19 / 11 / 89$ & $78,5(10 \mathrm{~cm})$ & 2,6 & 0 & +7.SUROESTE \\
\hline $18 / 02 / 81$ & $63(40 \mathrm{~cm})$ & -2 & $-6,2$ & 0. SURESTE \\
\hline $05 / 03 / 91$ & $81,1(55 \mathrm{~cm})$ & 3,8 & $-0,2$ & +5.SUROESTE \\
\hline $03 / 11 / 93$ & $52,7(3 \mathrm{~cm})$ & 3,2 & $-0,4$ & +4.SUROESTE \\
\hline $21 / 01 / 96$ & $150(98 \mathrm{~cm})$ & $-0,6$ & $-3,4$ & +3.SUROESTE \\
\hline $27 / 01 / 96$ & $80(10 \mathrm{~cm})$ & $-0,2$ & $-3,4$ & $+4 . S U R$ \\
\hline $05 / 02 / 96$ & $56,5(5 \mathrm{~cm})$ & 1,8 & -7 & 0.OESTE \\
\hline $20 / 12 / 96$ & $67,7(7 \mathrm{~cm})$ & 1 & $-1,2$ & +5.SUROSTE \\
\hline $21 / 12 / 96$ & $73,9(3 \mathrm{~cm})$ & 1 & $-0,2$ & +4.SUROESTE \\
\hline $27 / 01 / 98$ & $65(50 \mathrm{~cm})$ & $-2,2$ & -6 & O.SUROESTE \\
\hline $02 / 04 / 00$ & $74(15 \mathrm{~cm})$ & 0,8 & -2 & +6.SUROESTE \\
\hline $22 / 12 / 00$ & $85(40 \mathrm{~cm})$ & $-0,6$ & -2 & +4.SUROESTE \\
\hline $24 / 02 / 03$ & $58,8(14 \mathrm{~cm})$ & 0 & $-1,4$ & +4.SUROESTE \\
\hline $25 / 02 / 03$ & $65,8(30 \mathrm{~cm})$ & 0,7 & $-1,2$ & +3.SUROESTE \\
\hline $05 / 12 / 03$ & $70,7(35 \mathrm{~cm})$ & $-0,4$ & $-2,4$ & +3.SUROESTE \\
\hline $01 / 12 / 04$ & $50,2(25 \mathrm{~cm})$ & 1,8 & $-3,3$ & +5.SUROESTE \\
\hline $17 / 03 / 06$ & $58,1(0 \mathrm{~cm})$ & 4 & 1,1 & +5.SUROESTE \\
\hline 04/03/09 & $52(20 \mathrm{~cm})$ & $-0,4$ & -6 & +1. NOROESTE \\
\hline $21 / 12 / 10$ & $62,9(12 \mathrm{~cm})$ & 3,1 & $-0,6$ & +6.SUROESTE \\
\hline $16 / 01 / 13$ & $50,5(10 \mathrm{~cm})$ & 1,2 & $-3,1$ & +2. NOROESTE \\
\hline $19 / 01 / 13$ & $61(4 \mathrm{~cm})$ & 2,7 & $-4,3$ & +5. SUROESTE \\
\hline
\end{tabular}

Figura 3: Datos de precipitación y temperatura máxima y mínima del observatorio del Puerto de Navacerrada (1.888 $\mathrm{m}$ de altitud) de AEMET. Temperatura de $850 \mathrm{hPa}$ y viento obtenidos de los mapas de reanálisis de wetterzentrale (http://www.wetterzentrale.de) 
En cuanto al número de días en los que la nieve cubre el suelo se contabilizan los días en los que el espesor de la nieve fue igual o mayor de $5 \mathrm{~cm}$ para evitar posibles errores en la serie debidos a diferentes criterios en la medida de esta variable. Se considera día con el suelo cubierto de nieve aquel en el que el suelo permanece nevado en un porcentaje igual o superior al $50 \%$. Este parámetro es bastante subjetivo a la hora de cuantificarlo ya que hay muchos días en los que el manto de nieve es irregular y no cubre el suelo por completo. Como se observa en la figura 4 , el número de días con espesor de nieve igual o superior a $5 \mathrm{~cm}$ varía entre un mínimo de menos de 20 días en el invierno 1994-1995 y un máximo de 182 días en el invierno 1990-1991.

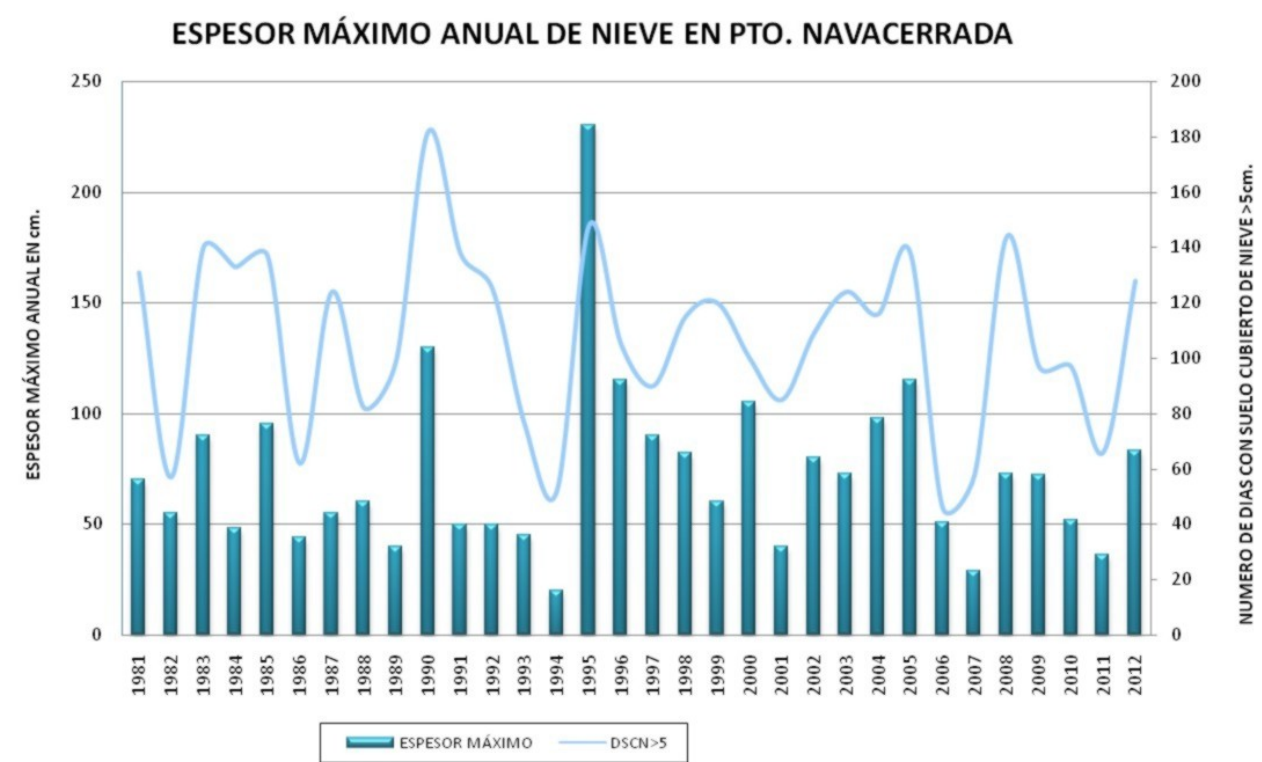

Figura 4: Datos del observatorio del Puerto de Navacerrada (1.888 m de altitud) de AEMET. Elaboración propia.

Cómo se vio anteriormente, la nieve tiende a acumularse a sotavento de los vientos dominantes. Por lo tanto, en el Macizo de Peñalara las acumulaciones más importantes tienden a formarse en la zona de los circos que tienen orientación este (nordeste a sureste). En la zona cercana a las cumbres, a sotavento de los vientos del oeste, se forman importantes cornisas y placas en las que la acumulación de nieve es muy intensa, de más de una decena de metros de espesor.

Cuándo las acumulaciones son importantes pueden formarse nichos de nivación sobre el manto de alteración. En la Sierra de Guadarrama, los nichos de nivación son abundantes y han sido estudiados en detalle (Palacios et al., 2006).

También hay otra zona de acumulación importante en la hoya situada en el extremo norte del Macizo. Esta hoya es también un circo glaciar, menos marcado que los de la cara este, pero más 
amplio; la nieve se acumula en la cabecera del mismo, en la parte superior de los grandes debris flows existentes y en los dispersos hoyos nivales (Palacios et al., 2006).

Existe otra importante zona de acumulación sobre el nicho nival del arroyo del Infierno entre Peña Citores y Dos Hermanas.

\section{METODOLOGÍA.}

Para determinar las zonas propensas al desencadenamiento de aludes se aplicará la metodología utilizada por el Ministerio de Agricultura francés (CEMAGREF) y el Instituto Geológico de Cataluña (IGC). Consta de 3 fases:

1. La fotointerpretación. Estudio e interpretación de fotografías aéreas e imágenes de satélite para determinar la morfología de las laderas, la cubierta forestal, la cubierta nivosa y elaboración de una cartografía de los aludes observados.

En este trabajo se han utilizado las ortofotos digitales de los vuelos PNOA, en formato TIFF con el correspondiente fichero TFW de georreferenciación del Instituto Geográfico Nacional (IGN) con tamaño de píxel $0.25 \mathrm{~m}$.

A partir de este material y con la ayuda de los Sistemas de Información Geográfica (SIG), se ha realizado una cartografía de pendientes, bosques densos, orientaciones favorables a la formación de placas, insolación potencial y se han cartografiado los aludes observados.

También se consultaron imágenes del satélite SPOT- 5 de $5 \mathrm{~m}$ de resolución espacial en modo pancromático para comprobar la extensión del terreno cubierto por la nieve. Como cartografía digital base para obtener dichos productos se ha hecho uso del Modelo digital del Terreno (MDT) suministrado por el IGN, con paso de malla de $5 \mathrm{~m}$, formato de archivo ASCII matriz ESRI (agr), distribución oficial de hojas 1:25.000 y sistema geodésico de referencia ETRS89.

2. Interpretación de campo. Consiste en identificar sobre el terreno las zonas de aludes previamente determinadas mediante fotointerpretación. Este trabajo se realiza en ausencia de nieve para poder observar de forma minuciosa la morfología de la ladera.

3. Encuestas a la población: La encuesta a la población permite obtener información sobre los diferentes episodios de aludes (tipo, frecuencia, época de caída, etc.), y sus límites.

La aplicación de estas tres fases al Macizo de Peñalara ha sido la siguiente: 
1.- Fotointerpretación de distintas variables geoecológicas.

- Vegetación. Es uno de los criterios directos más importantes para la delimitación de zonas probables de aludes. En primer lugar, las trazas del paso de aludes permanecen en la vegetación, dando lugar a zonas con ausencia total de ésta cuando el fenómeno es frecuente. Además, el porte y la densidad de la vegetación son factores muy importantes en relación con el desencadenamiento de aludes. Las zonas cubiertas de pasto serán las más favorables, seguidas de las masas densas de arbustos. Los bosques cerrados son los menos proclives a registrar aludes, aunque pueden verse afectados por avalanchas desencadenadas en cotas superiores, fuera del bosque (Palomo, 2007).

Siguiendo criterios biogeográficos, el Macizo de Peñalara se encuentra clasificado en la subregión Mediterránea occidental dentro de la provincia Carpetano - Ibérico - Leonesa, subprovincia Carpetana, Sector Guadarrámico, subsector Guadarramense, distrito Paularense. En función de la altitud se pueden distinguir dos cinturones de vegetación, el Oromediterráneo, entre 1.800 y 2.150 metros, y el Criomediterráneo, por encima de los 2.150 metros (RivasMartínez, 1963).

En términos generales, la vegetación típica del Macizo de Peñalara está constituida por bosques de pinar (Pinus sylvestris) en las cotas más bajas y por matorrales de enebro rastrero (Juniperus communis subsp. alpina), cambroño (Adenocarpus hispanicus) y piorno (Cytisus oromediterraneus) en las superiores.

La distribución de la vegetación está condicionada por factores geomorfológicos, climatológicos y nivológicos. El límite forestal en las vertientes orientadas al sur está situado en torno a los 2.100 metros, mientras que en las vertientes orientales del Macizo se encuentra alrededor de los 1.800 metros, por debajo de las áreas glaciadas (Obermaier y Carandell, 1917).

La importancia de la cubierta vegetal para el control de los aludes es clara y ha sido destacada por numerosos autores. En algunas zonas de Estados Unidos se ha observado una fuerte reducción de avalanchas en zonas colonizadas por bosques y, por el contrario, un aumento de los mismos en zonas deforestadas. En sectores del Pirineo se potencia la presencia de densos bosques como un elemento protector frente a ellos (Santos et al., 2010). 
Se ha procedido a la digitalización y posterior cartografiado del área ocupada por los bosques de Pinus Sylvestris, a partir de las fotografías aéreas PNOA del IGN.

En el presente trabajo se consideran áreas favorables al desencadenamiento de aludes aquellas en las que las masas forestales están ausentes, en concreto las que se encuentran por encima del límite forestal y, por el contrario, se ha supuesto que la presencia de bosques inhibe este proceso(ANEXO I, figura a.1).

- Características del terreno. La superficie del Macizo es rugosa en general. En las zonas menos afectadas por procesos glaciares o periglaciares permanece el manto de alteración. Sobre dicho manto se desarrolla un sotobosque de enebros rastreros (Juniperus communis subsp. alpina) y piornales (Cytisus oromediterraneus) que permite que la nieve se "agarre" bien al suelo, siendo una buena defensa contra los aludes de fondo. En otras áreas no glaciarizadas, el manto de alteración aparece cubierto de extensas pedreras constituidas por bloques periglaciares, como el campo de bloques de la vertiente noroeste. Estas pedreras también constituyen un buen anclaje para la nieve. En las áreas glaciadas el manto de alteración ha sido barrido, de forma más intensa en las hoyas de la Laguna Grande y de Pepe Hernando, y aparecen afloramientos rocosos de la roca madre (gneis). En la superficie de cumbres la nieve no se acumula y tiende a trasladarse sobre ella y acumularse en su borde oriental, sobre todo en orientaciones noreste, formando grandes cornisas, que suelen adquirir sus máximas dimensiones a principios de la primavera. Se acumula en cotas intermedias en las que la erosión glaciar ha resaltado las líneas tectónicas, formando depresiones de sobre-excavación en ellas y escalones y umbrales entre ellas (Palacios, et al., 2006). Estos escalones tienden a romper las pendientes, formando zonas de acumulación de la nieve y de frenado a los aludes.

En consecuencia, el terreno de la zona de estudio puede considerarse rugoso y poco favorable al desencadenamiento de aludes de fondo, a diferencia de terrenos lisos y herbáceos mucho más propensos al deslizamiento de la nieve desde su base.

- Pendientes. En términos generales, los aludes se originan en zonas con pendientes que oscilan entre los $25^{\circ}$ y los $45^{\circ}$. Por debajo de $25^{\circ}$ el manto de nieve permanece estático a no ser que se produzcan situaciones atmosféricas inusuales que den lugar a nevadas extraordinarias. Por encima de los $45^{\circ}$ la nieve se purga de forma natural, depositándose en niveles inferiores. Sin embargo, este es un factor que depende mucho del tipo de alud que estemos considerando. Así, los aludes de nieve reciente son más frecuentes en zonas con pendientes superiores a $45^{\circ}$, los aludes de placa se desencadenan con pendientes mayores o iguales a $30^{\circ}$ y los aludes de fusión pueden originarse con pendientes aún menores, incluso de $25^{\circ}$ (ANEXO I, figuras a.3, a.4 y a.5). 
Para detectar estas zonas, en primer lugar, se ha realizado a partir del MDE y con el Sistema de Información Geográfica ArcGIS, un mapa de pendientes de la zona de estudio. Posteriormente este mapa raster generado se ha reclasificado seleccionando las pendientes superiores a $25^{\circ}$, $30^{\circ}$ y $45^{\circ}$.

- Orientaciones. Es una variable que más que determinar el desencadenamiento de aludes condiciona el tipo de alud que se produce. Como se vio anteriormente, la nieve tiende a acumularse a sotavento de los obstáculos que encuentra. En el Macizo de Peñalara lo hace, en general, en los orientados al este (desde el nordeste al sureste), a sotavento de los vientos generales del oeste (desde el noroeste al suroeste). Esta orientación es, por lo tanto, favorable para la formación de cornisas y placas de viento y, en consecuencia, para el desencadenamiento de aludes de placa (figura 5).

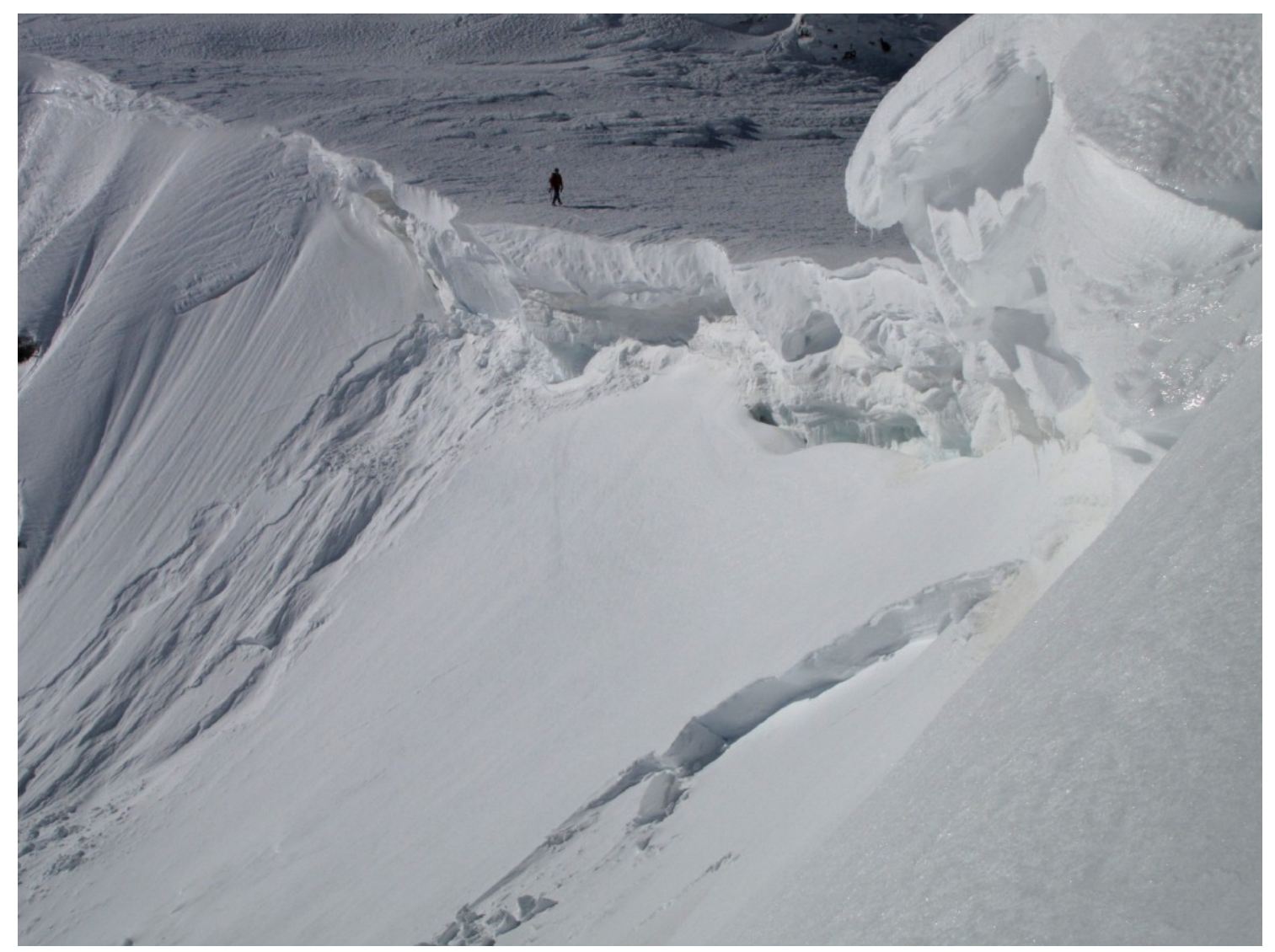

Figura 5: Ejemplos de cornisas. Autor: Luis Pantoja.

Para realizar el mapa de orientaciones se hizo uso del MDE. Utilizando la herramienta orientaciones del ArcGIS se obtuvo la orientación de cada pixel del MDE (ANEXO I, figura a.6).

- Insolación potencial. La radiación solar condiciona la temperatura de la superficie de la nieve y, por consiguiente, altera la evolución del manto de nieve y su metamorfosis. La incorporación 
de esta variable permite introducir un factor esencial en la inestabilidad del manto nival (Julián y Chueca, 2010).

La menor insolación ralentiza la evolución de la nieve recién caída y puede favorecer los aludes de nieve reciente así como la persistencia de las placas de hielo, Contrariamente, la mayor insolación hace que la nieve evolucione más rápidamente y puede favorecer los aludes de fusión.

El mapa de radiación potencial lo hemos obtenido a partir del MDE utilizando el módulo de ArcGIS "Area Solar Radiation". Esta herramienta nos genera un fichero ráster en el que a cada celda del MDE se le asigna un valor de radiación potencial total (directa más difusa). Para calcular el valor de la insolación potencial se tiene en cuenta las características del terreno del MDE: latitud, altitud, orientación, sombra generada por la topografía y trayectoria solar (época del año). Se ha considerado el periodo que va entre noviembre y marzo, en el que se desencadenan la mayor parte de los aludes.

En la figura 6 aparece el histograma de la insolación potencial acumulada entre noviembre y mayo en el Macizo de Peñalara.

INSOLACIÓN POTENCIAL ACUMULADA DE NOVIEMBRE A MAYO

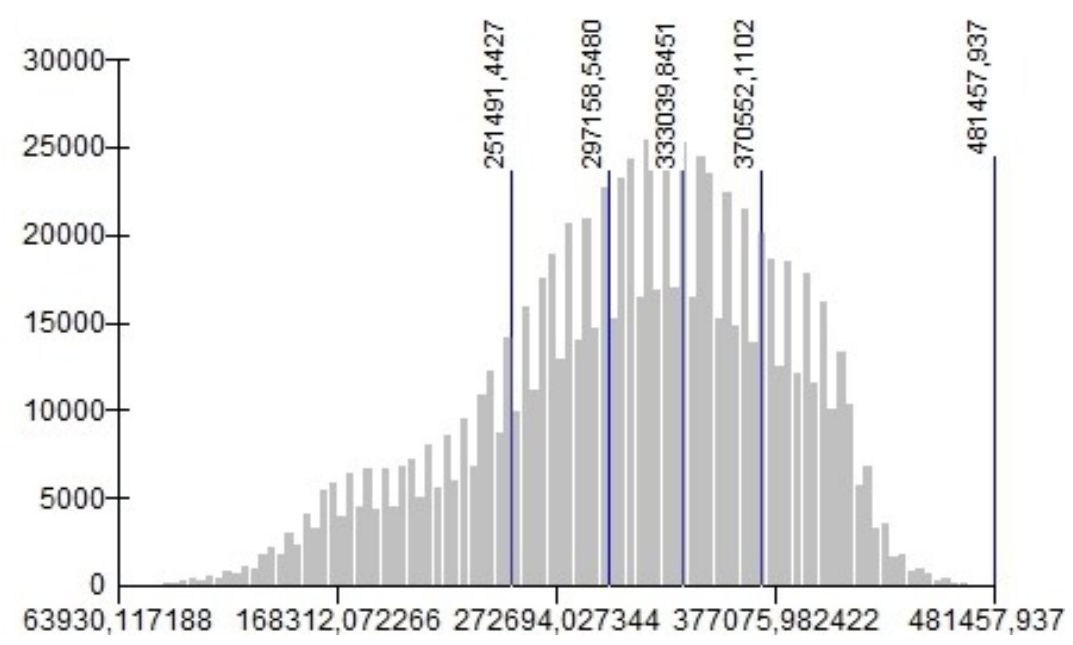

Figura 6: Histograma de la insolación potencial de noviembre a mayo en el Macizo de Peñalara.

En la figura 6 también aparecen los valores de los quintiles que dividen a la muestra en cinco grupos con el mismo número de elementos. Se ha considerado que los pixeles con insolación mínima son los situados en el primer quintil (Insolación potencial acumulada inferior a $251.491,44 \mathrm{Wh} / \mathrm{m}^{2}$ y los píxeles con insolación máxima son los que pertenecen al 
quinto quintil (insolación potencial acumulada superior a $370.552,11) \mathrm{Wh} / \mathrm{m}^{2}$ (ANEXO I, figura a.7).

\section{2.- Interpretación de campo}

En el Macizo de Peñalara, desde el año 2009, se realizan sondeos nivológicos por parte del Grupo de predicción de aludes de la Delegación de la Agencia Estatal de Meteorología en Madrid y por personal del Parque de Peñalara. A dichos sondeos, que se realizan semanalmente, se les añade información complementaria como test de estabilidad de la nieve y aludes observados.

Además, se realizan observaciones adicionales cuando las condiciones nivológicas lo hacen necesario. De esta forma, se efectúan frecuentes visitas al Macizo y se comprueba la existencia de depósitos de nieve, fracturas en placas de nieve, o cualquier otra señal que nos indique que se han producido avalanchas. Estas observaciones permiten tener un conocimiento del estado de la nieve y de las características de las avalanchas que se producen.

\section{3.- Encuestas a la población}

Se ha recopilado información del Grupo Especial de Rescate de la Comunidad de Madrid (GERA), el Grupo de Rescate en Montaña de la Guardia Civil (GREIM), la Guardería Forestal del Parque Natural, de guías de montaña, y de excursionistas y montañeros expertos conocedores de la zona. ${ }^{1}$

Partiendo de la información recopilada directamente en el campo o mediante encuestas se ha elaborado una base de datos y se ha realizado una cartografía de aludes observados. Con ayuda del SIG, se ha obtenido una serie de medidas relativas a las dimensiones de estos aludes (longitud, cota máxima, cota mínima, desnivel, área afectada). Esto nos permite adquirir un conocimiento previo de las características de los aludes que se producen en el Macizo.

Para la determinación del tamaño de los aludes se ha utilizado la tabla propuesta por la EAWS (European Avalanche Warning Services), en la que el cifrado está vinculado tanto al grupo mayoritario como a la presencia de aludes de mayores dimensiones (figura 7).

El tamaño de los aludes, clasificado en una escala de 1 a 5 , se puede establecer en función de tres criterios distintos pero complementarios. El primero de ellos tiene en cuenta la zona de llegada, distinguiendo fundamentalmente según se trate de ladera o fondo de valle y está en directa relación con la longitud de la trayectoria recorrida por el alud y el volumen de nieve movilizado (tercer criterio). A su vez, estos dos criterios están asociados a unos determinados daños potenciales sobre las personas u otros elementos y sobre el entorno. El rango de efectos de los aludes va desde aquellos relativamente inofensivos, aunque capaces de tirar al suelo a una persona (purgas o coladas) a los aludes muy grandes, capaces de modificar sustancialmente el paisaje y

\footnotetext{
${ }^{1}$ Colaboración especial de Luis Pantoja, Alberto Pantoja y personal del Parque de Peñalara.
} 
producir un desastre. Nuevamente es necesario referenciar la longitud de un alud a los aludes habituales y los extremos de una zona, para lo cual es indispensable disponer de una base de datos de aludes de la zona.

\begin{tabular}{|c|c|c|c|}
\hline $\begin{array}{l}\text { Tamaño y } \\
\text { Nombre }\end{array}$ & $\begin{array}{c}\text { Clasificación según la zona de } \\
\text { llegada }\end{array}$ & $\begin{array}{c}\text { Clasificación según el daño } \\
\text { potencial }\end{array}$ & $\begin{array}{l}\text { Clasificación } \\
\text { cuantitativa }\end{array}$ \\
\hline $\begin{array}{l}\text { 1. Purga o } \\
\text { colada }\end{array}$ & $\begin{array}{l}\text { Acumulación de nieve sin peligro de } \\
\text { enterrar pero con peligro de caída. }\end{array}$ & $\begin{array}{l}\text { Relativamente inofensivo } \\
\text { para las personas. }\end{array}$ & $\begin{array}{l}\text { Longitud }<50 \mathrm{~m} \text {, } \\
\text { volumen }<100 \mathrm{~m}^{3}\end{array}$ \\
\hline $\begin{array}{c}\text { 2.Alud } \\
\text { pequeño }\end{array}$ & El alud se para en la pendiente. & $\begin{array}{l}\text { Puede enterrar, herir o } \\
\text { matar a una persona. }\end{array}$ & $\begin{array}{l}\text { Longitud }<100 \mathrm{~m} \text {, } \\
\text { volumen }<1.000 \mathrm{~m}^{3}\end{array}$ \\
\hline $\begin{array}{c}\text { 3.Alud } \\
\text { mediano }\end{array}$ & $\begin{array}{l}\text { El alud alcanza el final de la } \\
\text { pendiente. }\end{array}$ & $\begin{array}{l}\text { Puede enterrar o destruir un } \\
\text { coche, causar daños a un } \\
\text { camión, destruir un edificio } \\
\text { pequeño o romper un } \\
\text { número pequeño de árboles. }\end{array}$ & $\begin{array}{l}\text { Longitud }<1.000 \mathrm{~m} \\
\text { volumen }<10.000 \mathrm{~m}^{3}\end{array}$ \\
\hline $\begin{array}{l}\text { 4. Alud } \\
\text { grande }\end{array}$ & $\begin{array}{l}\text { El alud atraviesa zonas planas } \\
(\text { considerablemente por debajo de } \\
\left.30^{\circ}\right) \text { una distancia mayor de } 50 \mathrm{~m} \text { y } \\
\text { puede llegar al fondo de valle. }\end{array}$ & \begin{tabular}{|l|} 
Puede enterrar y destruir un \\
vagón de tren, un camión \\
grande, varios edificios o \\
una parte de bosque.
\end{tabular} & $\begin{array}{l}\text { Longitud } \sim 1-2 \mathrm{~km}, \\
\text { volumen }<100.000 \mathrm{~m}^{3}\end{array}$ \\
\hline $\begin{array}{l}\text { 5.Alud } \\
\text { muy } \\
\text { grande }\end{array}$ & $\begin{array}{l}\text { Llega al fondo de valle. Alud más } \\
\text { grande conocido. }\end{array}$ & $\begin{array}{l}\text { Puede modificar el paisaje. } \\
\text { Posibilidad de daños } \\
\text { desastrosos. }\end{array}$ & $\begin{array}{l}\text { Longitud } \sim 3 \mathrm{~km}, \\
\text { volumen }>100.000 \mathrm{~m}^{3}\end{array}$ \\
\hline
\end{tabular}

Figura 7: Tamaño de los aludes según la EAWS (European Avalanche Warning Services).

La cartografía de zonas favorables al desencadenamiento de aludes se ha elaborado siguiendo la metodología empleada por Palomo et al., (2008). Según esta metodología, los factores que influyen en el desencadenamiento de un alud pueden clasificarse en necesarios y de intensificación.

Los factores necesarios son aquellos cuya ausencia hacen muy improbable el desencadenamiento de aludes. En el área de estudio se han considerado factores necesarios las pendientes favorables y la ausencia de bosques densos. Así, para que se desencadene un alud tiene que existir una pendiente mínima que depende del tipo de alud. Además, se considera que un alud no se desencadena en el interior de un bosque denso ya que éstos impiden la formación de placas de nieve, favorecen la evolución de la nieve en las hojas y ramas impidiendo la llegada al suelo de nieve reciente y la presencia de árboles inhibe el desencadenamiento de aludes de fusión. En consecuencia, la ausencia de bosque se considera un factor favorable a la ocurrencia de aludes.

Los factores de intensificación son factores que no condicionan el desencadenamiento pero sí que aumentan la probabilidad de que éste se produzca. Estos factores varían según el tipo de alud, y entre ellos se consideran las zonas más propicias a que se acumule la nieve, las orientaciones favorables y la insolación potencial. 
Todos los factores (tanto los necesarios como los de intensificación) toman el valor 1 en el pixel cuando se cumplen y el valor 0 si no se cumplen.

En la figura 8 aparecen, resumidos, los criterios que se han considerado para la elaboración de las cartografías así como la combinación de ellos utilizada, dependiendo del tipo de alud.

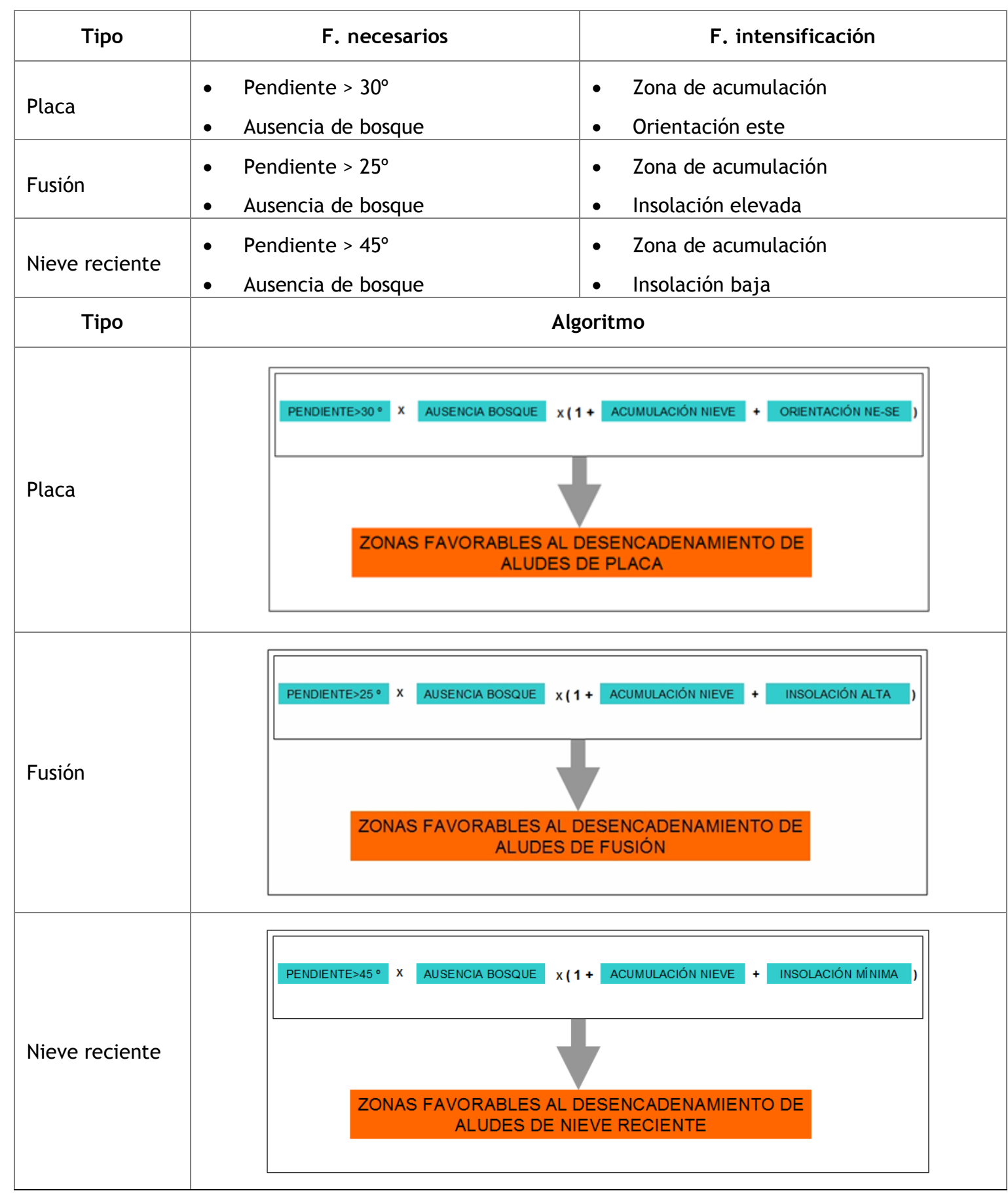

Figura 8: Variables utilizadas en la elaboración de la cartografía de zonas favorables al desencadenamiento de aludes. 
Con esta metodología se pueden establecer cuatro categorías de probabilidad de desencadenamiento que son aplicables a todos los mapas obtenidos (figura 9).

Se considera una probabilidad de desencadenamiento baja en el caso en el que al menos uno de los factores necesarios tome valor 0 . La probabilidad es moderada cuando los factores necesarios tienen valor 1 pero los de intensificación tienen valor 0 . La probabilidad alta corresponde a las zonas en las que los factores necesarios y uno de los de intensificación tienen valor 1. La probabilidad muy alta aparece en las áreas en las que todos los factores, tanto los necesarios como los de intensificación toman valor 1.

\section{Probabilidad desencadenamiento aludes}

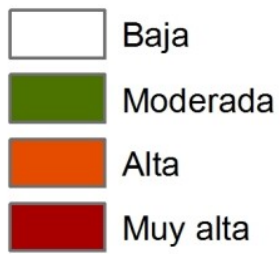

Figura 9: Escala del mapa de áreas de desencadenamiento de aludes de placa. Elaboración propia.

Además, se ha elaborado una cartografía general de desencadenamiento de riesgo de aludes, sin distinción de los tipos. Las variables consideradas y el algoritmo utilizado se resumen en la figura 10.

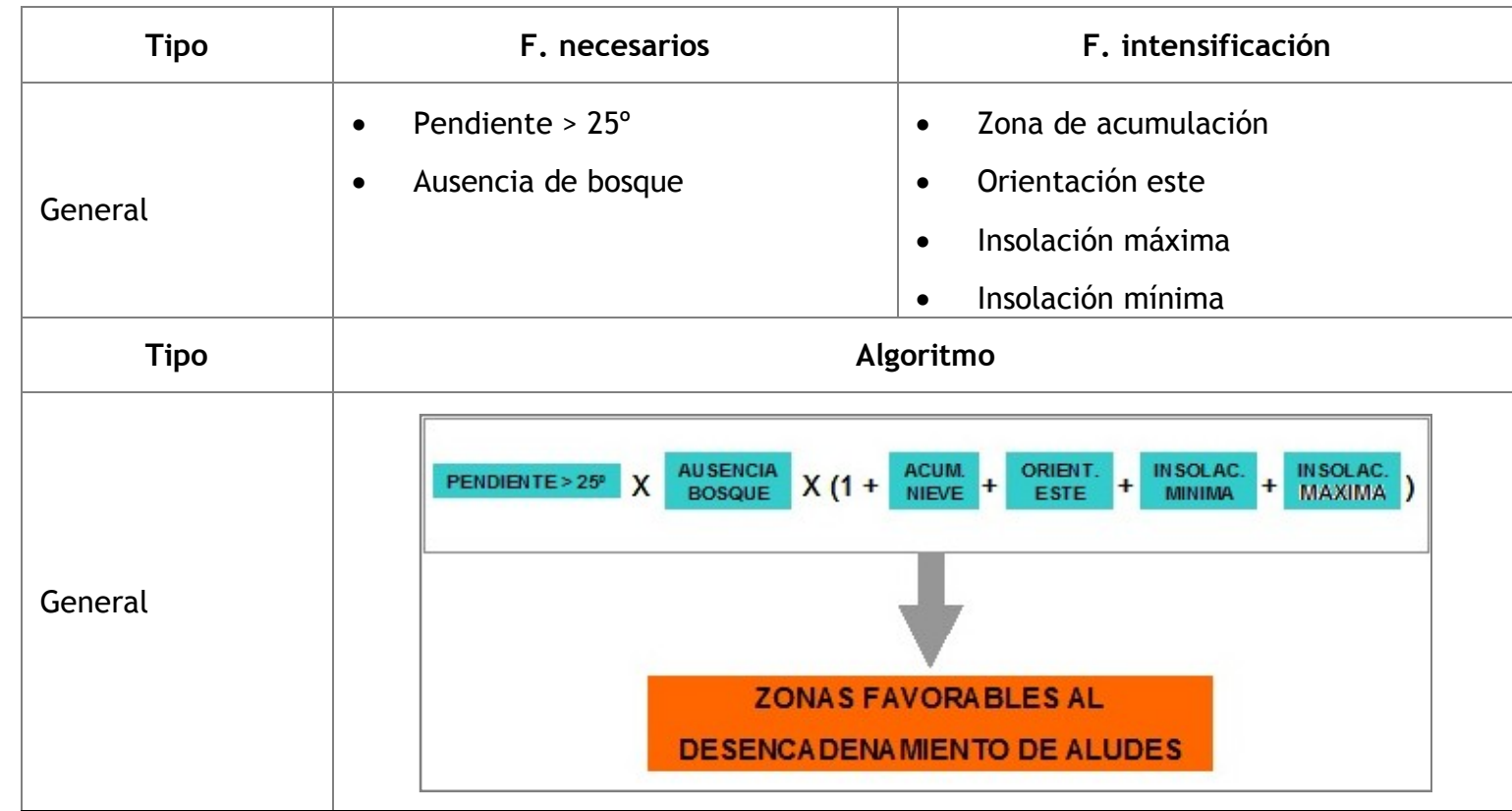

Figura 10: Variables utilizadas en la elaboración de la cartografía de zonas favorables al desencadenamiento de aludes. 
En el caso de las pendientes se ha supuesto que la pendiente mínima es $25^{\circ}$, que es el valor mínimo para que se desencadene un alud de cualquier tipo. Como factores de intensificación se consideran todos los que contribuyen a cualquier tipo de alud.

Si se tiene en cuenta que hay dos factores que son excluyentes entre sí (insolación mínima e insolación máxima) y nunca toman simultáneamente el valor 1 , cada píxel podrá tomar un valor entre 0 y 4 . Por lo tanto se pueden establecer cinco categorías.

El Centro de Avalanchas de Canadá (Canadian Avalanche Center) ha establecido una propuesta de clasificación del terreno, siguiendo criterios geomorfológicos y nivológicos, que tiene como objetivo detectar áreas favorables al desencadenamiento de aludes (figura 11). La escala está pensada para ayudar a los montañeros a evaluar la exposición del terreno a los aludes en los Parques de Canadá y permite evaluar la severidad de un itinerario o de una zona con tres clases de terreno (simple, desafiante o complejo) que describen la exposición a los posibles peligros de aludes (Campbell y Marshall, 2010; Statham y MacMahon, 2004).

Estos criterios se han aplicado al Macizo de Peñalara y los resultados se han comparado con los mapas obtenidos anteriormente como comprobaremos más adelante.

\begin{tabular}{|c|c|c|c|}
\hline VARIABLES & 1.Simple & 2.Desafiante & 3.Complejo \\
\hline Pendiente & Generalmente $<30^{\circ}$ & $\begin{array}{l}\text { Generalmente pequeñas. } \\
\text { Algunas pendientes } \\
\text { aisladas }>35^{\circ}\end{array}$ & $\begin{array}{l}\text { Variable. Gran parte del } \\
\text { terreno con pendientes }>35^{\circ}\end{array}$ \\
\hline Forma de la ladera & Uniforme. & Algunas convexidades. & $\begin{array}{l}\text { Irregular, con muchas } \\
\text { convexidades y concavidades }\end{array}$ \\
\hline Densidad del arbolado & Bosque denso. & $\begin{array}{l}\text { Terreno en general } \\
\text { abierto. }\end{array}$ & $\begin{array}{l}\text { Grandes extensiones de } \\
\text { terreno abierto o árboles } \\
\text { aislados. }\end{array}$ \\
\hline Trampas del terreno & $\begin{array}{l}\text { Mínimas, algunos } \\
\text { arroyos o pequeños } \\
\text { barrancos. }\end{array}$ & $\begin{array}{l}\text { Algunas depresiones, } \\
\text { barrancos y/o zonas } \\
\text { superiores de trayectos de } \\
\text { aludes }\end{array}$ & $\begin{array}{l}\text { Muchas depresiones, } \\
\text { acantilados, declives ocultas } \\
\text { sobre barrancos, cornisas. }\end{array}$ \\
\hline $\begin{array}{l}\text { Frecuencia } \\
\text { aludes.(aludes:años) }\end{array}$ & $1: 30>=$ tamaño 2 & $\begin{array}{l}1: 1<\text { tamaño } 2 \\
1: 3>=\text { tamaño } 2\end{array}$ & $\begin{array}{l}1: 1<\text { tamaño } 3 \\
1: 1>=\text { tamaño } 3\end{array}$ \\
\hline $\begin{array}{l}\text { Densidad de zonas de } \\
\text { salida de aludes }\end{array}$ & $\begin{array}{l}\text { Poco terreno } \\
\text { abierto. }\end{array}$ & $\begin{array}{l}\text { Terreno abierto. Algunas } \\
\text { zonas de trayecto de } \\
\text { aludes llegan al fondo del } \\
\text { valle. }\end{array}$ & $\begin{array}{l}\text { Grandes extensiones de } \\
\text { terreno abierto. Muchas zonas } \\
\text { de trayecto de aludes llegan al } \\
\text { fondo del valle. }\end{array}$ \\
\hline $\begin{array}{l}\text { Características de las } \\
\text { zonas erosionadas por } \\
\text { aludes }\end{array}$ & $\begin{array}{l}\text { Áreas aisladas y bien } \\
\text { definidas; } \\
\text { transiciones suaves y } \\
\text { depósitos } \\
\text { diseminados. }\end{array}$ & $\begin{array}{l}\text { Transiciones abruptas o } \\
\text { depósitos en el fondo de } \\
\text { depresiones profundas. }\end{array}$ & $\begin{array}{l}\text { Múltiples zonas convergentes } \\
\text { de erosión, zona de deposición } \\
\text { confinada, bajo trayectos con } \\
\text { pendientes pronunciadas }\end{array}$ \\
\hline $\begin{array}{l}\text { Intersección con las } \\
\text { zonas de trayecto de } \\
\text { aludes }\end{array}$ & $\begin{array}{l}\text { Únicamente con } \\
\text { zonas de depósito. }\end{array}$ & $\begin{array}{l}\text { Con una única zona de } \\
\text { trayecto o varias } \\
\text { separadas entre sí. }\end{array}$ & $\begin{array}{l}\text { Con numerosas zonas de } \\
\text { trayecto, generalmente } \\
\text { superpuestas entre sí. }\end{array}$ \\
\hline
\end{tabular}




\begin{tabular}{|l|l|l|l|}
\hline \multicolumn{1}{|c|}{ VARIABLES } & \multicolumn{1}{|c|}{ 1.Simple } & \multicolumn{1}{|c|}{ 2.Desafiante } & \multicolumn{1}{c|}{ 3.Complejo } \\
\hline Opciones de ruta & $\begin{array}{l}\text { Numerosas rutas } \\
\text { posibles. El terreno } \\
\text { permite múltiples } \\
\text { opciones. }\end{array}$ & $\begin{array}{l}\text { Varias opciones con } \\
\text { distintos niveles de } \\
\text { exposición. Existe la } \\
\text { posibilidad de evitar las } \\
\text { zonas de trayecto de } \\
\text { aludes. }\end{array}$ & $\begin{array}{l}\text { Oportunidades limitadas de } \\
\text { reducir la exposición, pasos } \\
\text { obligados. }\end{array}$ \\
\hline Tiempo de exposición & $\begin{array}{l}\text { Nulo o limitado al } \\
\text { tránsito por zonas } \\
\text { de depósito de } \\
\text { aludes. }\end{array}$ & $\begin{array}{l}\text { Exposición ocasional a } \\
\text { zonas de salida y } \\
\text { trayecto de aludes. }\end{array}$ & $\begin{array}{l}\text { Exposición frecuente a zonas } \\
\text { de salida y trayecto de } \\
\text { aludes. }\end{array}$ \\
\hline Glaciares & No hay glaciares & $\begin{array}{l}\text { Generalmente suave, con } \\
\text { bandas aisladas de grietas. }\end{array}$ & $\begin{array}{l}\text { Secciones de grietas con } \\
\text { roturas o muy inclinadas, } \\
\text { cascadas de hielo o seracs }\end{array}$ \\
\hline
\end{tabular}

Figura 11: Escala de Clasificación del terreno favorable al desencadenamiento de avalanchas (Avalanche Terrain Exposure Scale, ATES). Fuente: Centro de Avalanchas de Canadá (Canadian Avalanche Center. www. avalanche.ca)

Notar que cada descriptor aparece en la caracterización de un sólo tipo de terreno. Aunque, como el lector puede comprobar, cualquier zona montañosa puede tener características que correspondan a diferentes tipos de terrenos, a la hora de determinar cuál es su tipo se debe dar prioridad por defecto a aquellos descriptores que aparecen escritos en negrita y cursiva. Esta prioridad significa que un terreno caracterizado por un descriptor escrito en negrita y cursiva quedará automáticamente incluido en el tipo al que caracteriza dicho descriptor o en uno superior. El resto de descriptores tienen menor peso y no gozan de prioridad, pero deben considerarse en combinación con los demás factores. 


\section{RESULTADOS.}

\subsection{Aludes observados}

En la figura 12 aparecen cartografiados los aludes observados en el Macizo de Peñalara entre los años 2009 y 2013.

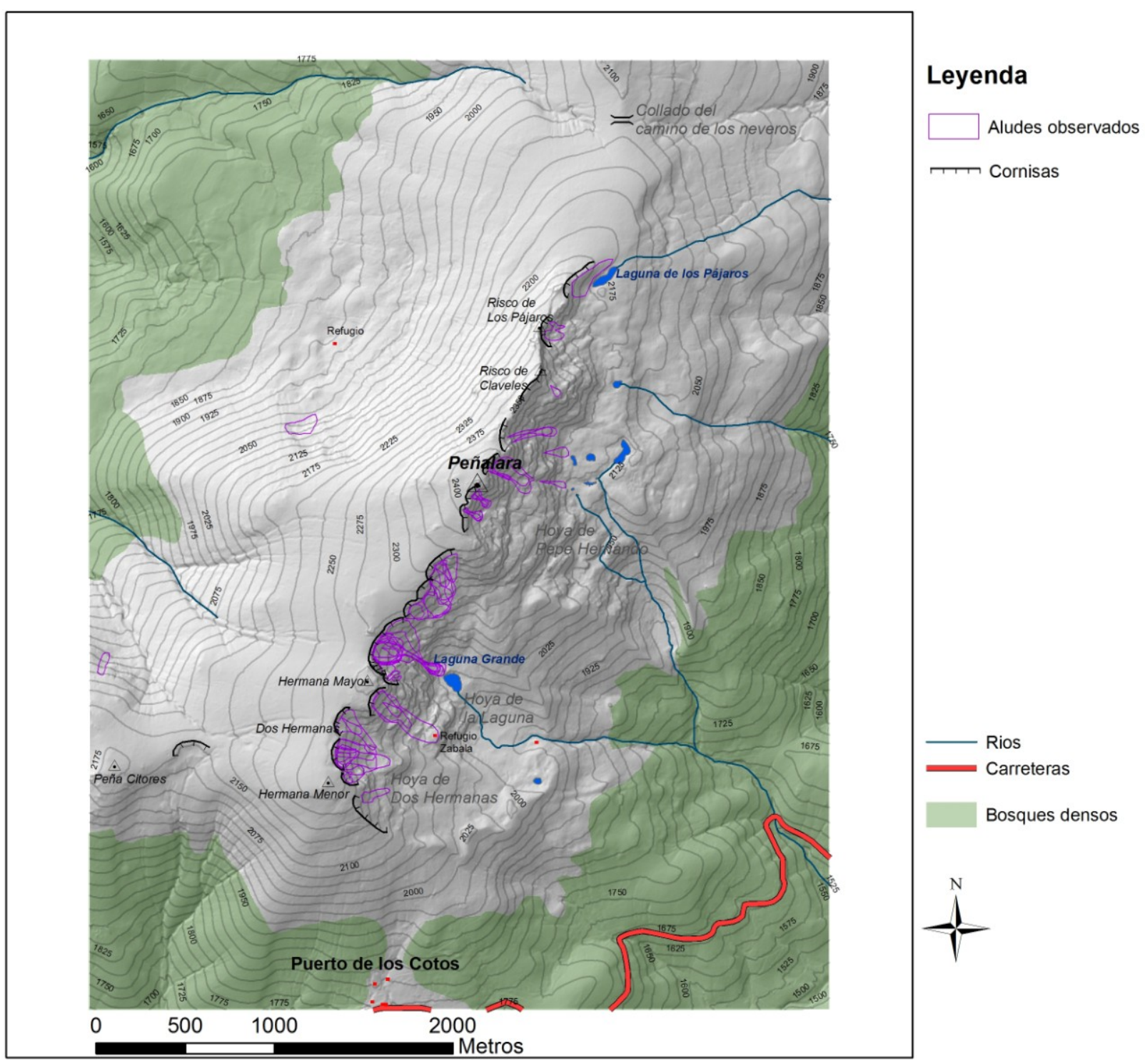

Figura 12: Mapa de aludes observados. Elaboración propia.

Podemos destacar la ausencia prácticamente total de aludes en la cara noroeste, siendo como veremos posteriormente, una zona moderadamente propensa al desencadenamiento de aludes. Las razones de esta ausencia de aludes pueden ser varias: en primer lugar la pendiente no es muy acusada; por otra parte no es una zona excesivamente propicia a la acumulación de nieve ni a la formación de placas de viento debido a su orientación a barlovento de los vientos dominantes; y, en 
tercer lugar, es una zona menos transitada y puede haberse desencadenado algún alud que haya pasado desapercibido. Esta última razón también puede explicar que en las hoyas glaciares del macizo hay más aludes observados que en las más occidentales, es decir, en las más próximas al Puerto de los Cotos que en las más alejadas a dicho Puerto.

Al cartografiar los aludes se trazó una línea desde la cota máxima a la mínima de cada uno de los aludes sobre el Modelo Digital de Elevaciones (MDE). A continuación se creó su perfil gráfico y se exportaron los datos de dicho perfil a una hoja de cálculo. De esta forma, se pueden obtener algunas estimaciones de la longitud y superficie abarcadas por las avalanchas (figura 13).

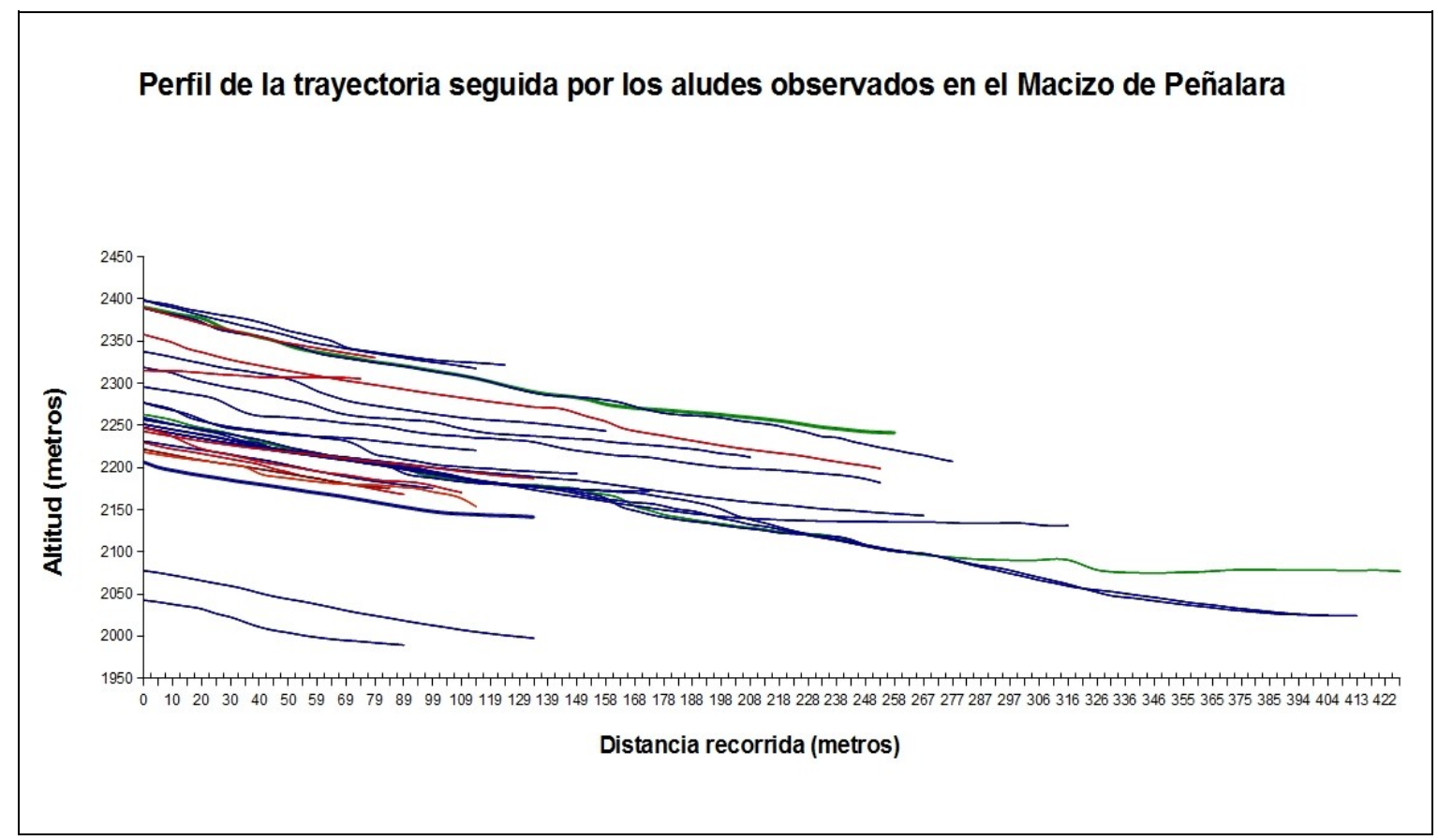

Figura 13: Perfil de los aludes observados en el Macizo de Peñalara. En azul los aludes de placa, en rojo los de fusión y en verde los de placa friable. Elaboración propia. 
En la figura 14, aparece, resumida, la información relativa a los aludes registrados en el Macizo de Peñalara.

\begin{tabular}{|c|c|c|c|c|c|}
\hline $\begin{array}{l}\text { Tipo } \\
\text { Alud }\end{array}$ & Longitud (m) & Cota máxima (m) & Cota mínima $(\mathrm{m})$ & Desnivel (m) & Superficie $\left(m^{2}\right)$ \\
\hline Placa & 163 & 2201 & 2111 & 90 & 6570 \\
\hline Placa & 315 & 2257 & 2131 & 126 & 42760 \\
\hline Placa & 262 & 2248 & 2143 & 105 & 19100 \\
\hline Placa & 259 & 2259 & 2099 & 160 & 19480 \\
\hline Placa & 262 & 2248 & 2143 & 105 & 17300 \\
\hline Placa & 422 & 2251 & 2023 & 228 & 28700 \\
\hline Placa & 160 & 2338 & 2242 & 96 & 9910 \\
\hline Placa & 200 & 2319 & 2212 & 107 & 18340 \\
\hline Placa & 150 & 2277 & 2181 & 96 & 31430 \\
\hline Placa & 304 & 2296 & 2182 & 114 & 33320 \\
\hline Placa & 85 & 2230 & 2168 & 62 & 1510 \\
\hline Placa & 112 & 2399 & 2318 & 81 & 4200 \\
\hline Placa & 280 & 2389 & 2207 & 182 & 23180 \\
\hline Placa & 110 & 2277 & 2221 & 56 & 6880 \\
\hline Placa & 98 & 2231 & 2176 & 56 & 17500 \\
\hline Placa & 89 & 2043 & 1989 & 53 & 12340 \\
\hline Placa & 128 & 2078 & 1998 & 80 & 4790 \\
\hline Placa & 407 & 2261 & 2024 & 237 & 32680 \\
\hline Placa & 414 & 2247 & 2024 & 223 & 27200 \\
\hline Placa & 115 & 2397 & 2321 & 76 & 3540 \\
\hline Placa & 81 & 2251 & 2172 & 79 & 16730 \\
\hline Fusión & 146 & 2217 & 2140 & 77 & 4433 \\
\hline Fusión & 250 & 2359 & 2197 & 162 & 5352 \\
\hline Fusión & 262 & 2346 & 2184 & 162 & 6635 \\
\hline Fusión & 139 & 2215 & 2141 & 74 & 4433 \\
\hline Fusión & 155 & 2212 & 2122 & 90 & 2462 \\
\hline Fusión & 89 & 2391 & 2327 & 64 & 1215 \\
\hline Fusión & 85 & 2392 & 2329 & 63 & 770 \\
\hline Fusión & 95 & 2226 & 2175 & 51 & 2244 \\
\hline Fusión & 125 & 2310 & 2237 & 73 & 2550 \\
\hline Fusión & 113 & 2246 & 2164 & 82 & 3647 \\
\hline Fusión & 136 & 2244 & 2186 & 58 & 3977 \\
\hline Fusión & 117 & 2218 & 2150 & 68 & 3552 \\
\hline P.friable & 255 & 2390 & 2241 & 149 & 22816 \\
\hline P.friable & 426 & 2263 & 2076 & 187 & 42734 \\
\hline
\end{tabular}

Figura 14: Características y dimensiones de los aludes observados en el Macizo de Peñalara.

Datos: AEMET. Elaboración propia.

La longitud media de los aludes observados es de $194 \mathrm{~m}$ aunque la mayor parte de ellos (el 63\%) tienen menos de $200 \mathrm{~m}$ de recorrido y sólo el $17 \%$ supera los $300 \mathrm{~m}$.

La cota de salida de los aludes observados es, en todos los casos, superior a $2000 \mathrm{~m}$. Solo en dos ocasiones la cota de salida ha sido inferior a $2.200 \mathrm{~m}$. 
La cota de llegada es, en un $94 \%$ de los casos, superior a los $2.000 \mathrm{~m}$. Sólo en dos desencadenamientos la cota de llegada fue inferior a $2.000 \mathrm{~m}$ y siempre estuvo por encima de 1900 m. La cota mínima alcanzada es de $1.980 \mathrm{~m}$.

La superficie afectada por los aludes presenta una alta variabilidad. El valor medio es de $13.837 \mathrm{~m}^{2}$ pero el $57 \%$ de los aludes observados no alcanzan este valor.

El tipo de alud más frecuente es el alud de placa. El 66\% de los aludes observados son de este tipo, de los cuales el $6 \%$ son de placa friable, un tipo de alud que presenta características conjuntas a los de placa y los de nieve reciente y el $34 \%$ de aludes son de fusión o nieve húmeda. No se han observado aludes de nieve reciente "puros", aunque si existen noticias de su ocurrencia en el Macizo como aludes que se inician como ruptura de una placa friable y evolucionan a aludes de nieve reciente polvo. El evento más importante se produjo en el mes de enero de 2009, en el que la nube pulverulenta paso por encima del Refugio de Zabala sin provocar ningún daño apreciable, pero sí algún accidentado.

De acuerdo con los criterios establecidos por la EAWS (figura 7) el tamaño de los aludes registrados en el Macizo varía desde coladas, pasando por aludes pequeños y medianos (los más habituales), hasta alguno grande.

En el Macizo de Peñalara los aludes de fusión observados se pueden clasificar, en cuanto a su tamaño, como coladas, aludes pequeños o medianos. No se han observado aludes de fusión de tamaño grande ni aludes de fondo. Los aludes de fondo son los que tienen mayor poder erosivo y dejan unas huellas perfectamente visibles en el terreno durante mucho tiempo. En el Macizo de Peñalara no se encuentran huellas de este tipo. Las razones por las que no se producen aludes de fondo en el Macizo son varias. Por un lado, como se vio en las características del terreno, no existen suelos herbáceos propensos al deslizamiento del manto desde su base; por otra parte, los canales por donde discurren los aludes no son lo suficientemente importantes para que la masa de nieve húmeda en movimiento adquiera la "fuerza" necesaria para arrastrar lo que encuentra a su paso; una tercera razón podría ser debida a la climatología propia de estas montañas. En concreto los continuos episodios de hielo-rehielo que se producen durante el invierno en el Macizo van humidificando y, por tanto, aumentando la densidad de las capas más profundas del manto. En estas condiciones, con un mismo contenido de agua líquida, la cohesión entre los granos es más fuerte que si se tratara de una nieve húmeda - primavera menos densa (Coleou et al., 1993).

Por lo tanto, en el Macizo de Peñalara sí se han observado aludes de fusión, pero no se han visto aludes de fondo ni señales de que se hayan producido en los últimos años. 


\subsection{Aludes de placa}

En la figura 15 aparece el mapa de zonas favorables al desencadenamiento de aludes de placa en el Macizo de Peñalara. Este mapa se ha elaborado siguiendo la metodología expuesta en la figura 8.

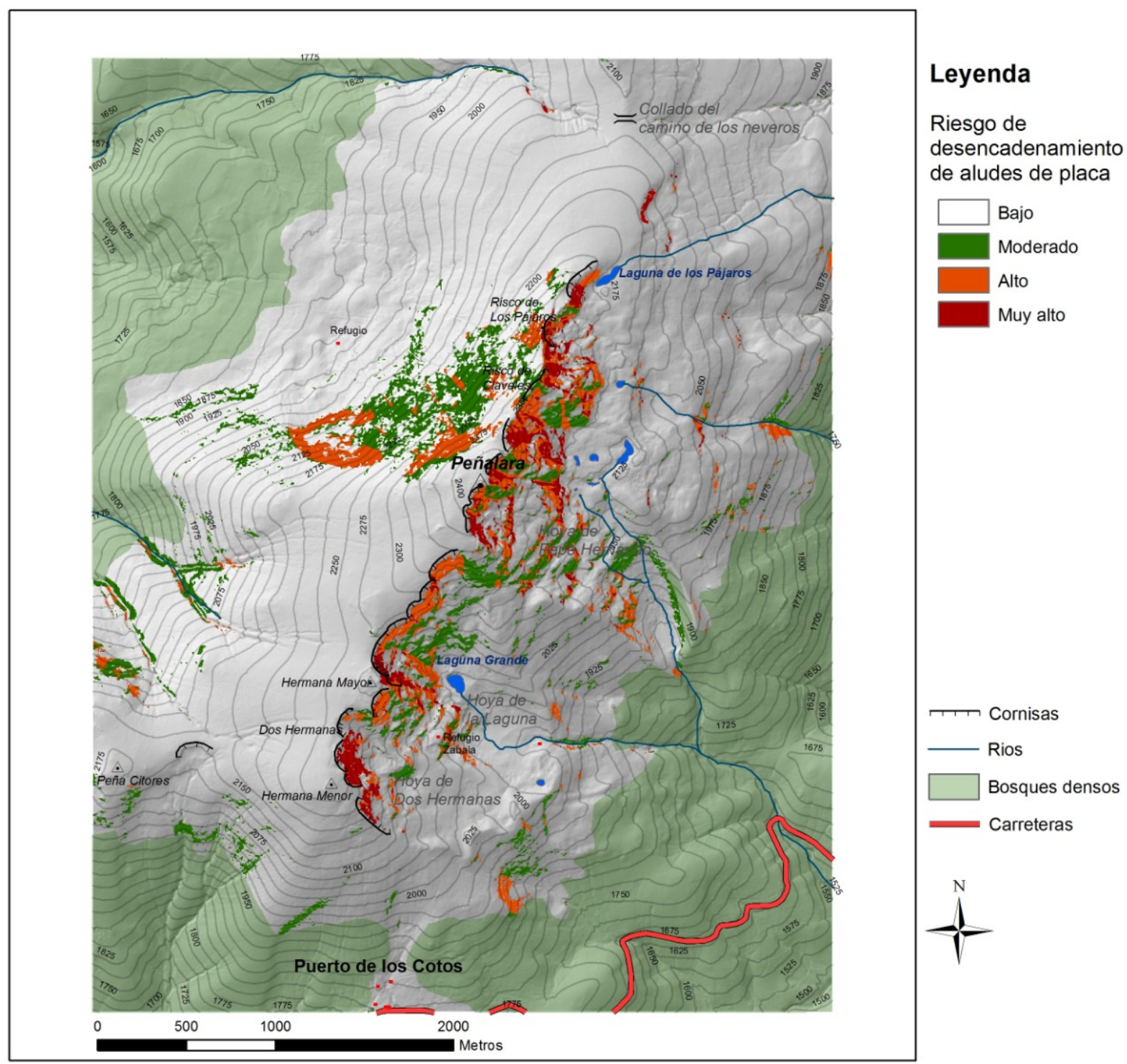

Figura 15: Mapa de áreas favorables al desencadenamiento de aludes de placa en el Macizo de Peñalara. Elaboración propia.

Los aludes de placa son los más frecuentes y, también, los que más accidentes provocan en el Macizo de Peñalara.

Pueden ser espontáneos o provocados, y, en ambos casos, se desencadenan debido a un sobrepeso sobre el manto nivoso que aumenta las fuerzas de tracción pendiente abajo y llegan a provocar una ruptura de la placa de nieve (dura o friable). Cuando el alud es espontáneo se suelen desencadenar por el sobrepeso producido por las precipitaciones (nevadas o lluvias). Cuando es provocado se 
pueden desencadenar bastante tiempo después de las nevadas, en este caso el sobrepeso puede ser provocado por el paso de animales, personas (esquiadores, excursionistas), por caída de cornisas o purgas de nieve (figura 16).

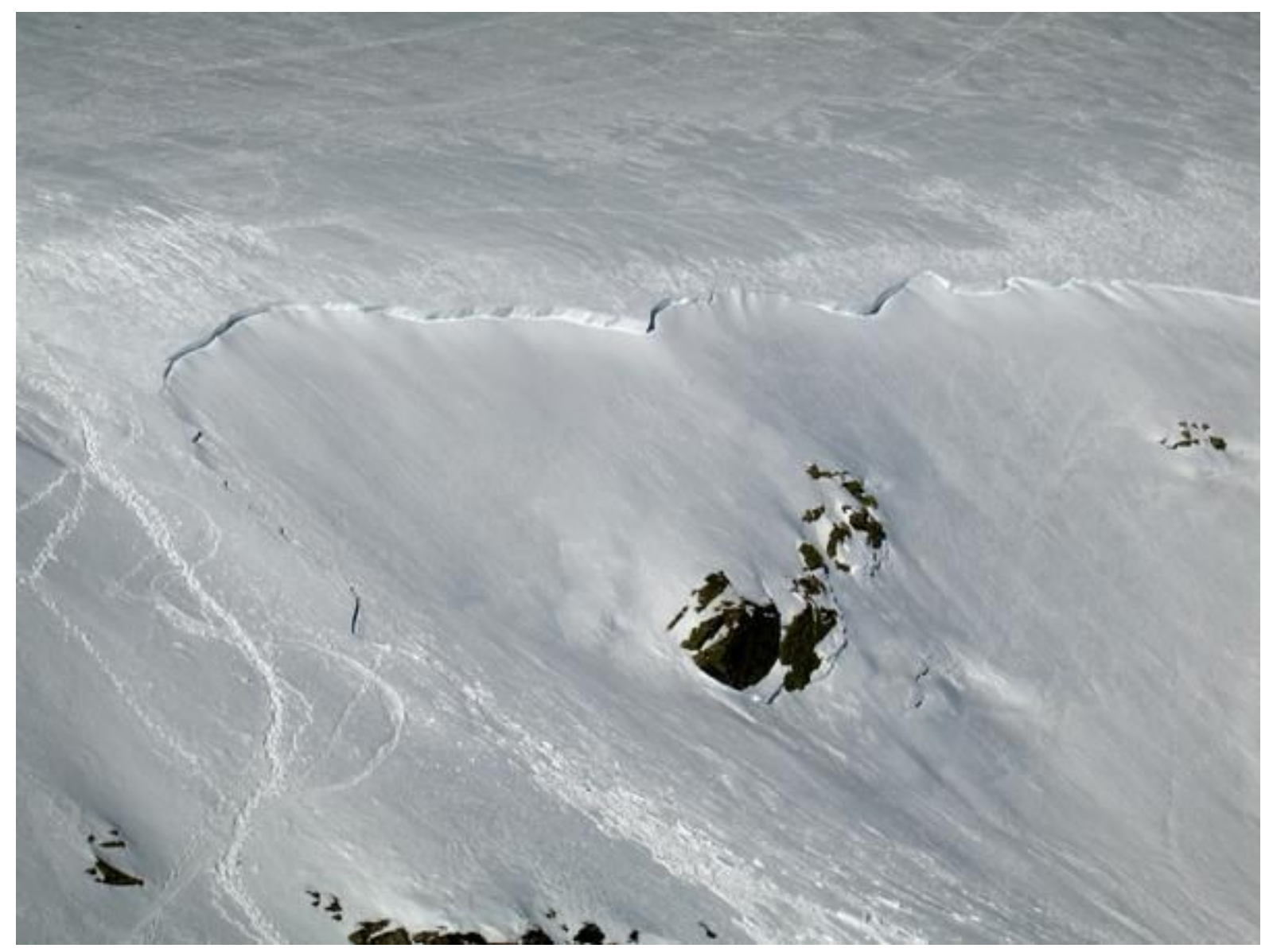

Figura 16: Ejemplo de alud de placa. Autor: Luis Pantoja.

En el mapa de la figura 15 se observa cómo el riesgo de desencadenamiento de aludes de placa es muy alto en unas pequeñas áreas de las zonas más elevadas de la vertiente oriental del Macizo de Peñalara, que coinciden aproximadamente con los nichos nivales situados en las cabeceras del circo de Dos Hermanas y del circo de Peñalara. En estas zonas la nieve persiste hasta el final de la temporada invernal, las pendientes son elevadas, la orientación es favorable a la formación de placas y la vegetación arbórea está ausente. La concurrencia de todos estos factores favorece la ocurrencia de aludes de placa.

El riesgo alto de desencadenamiento aparece en una estrecha franja situada inmediatamente por debajo de las cumbres del Macizo en las laderas orientadas al este y fuera de los nichos de nivación. 
Otra área con riesgo alto se sitúa en la cabecera de la hoya al norte del Macizo, con orientación norte. En esta zona, la acumulación es elevada, la pendiente favorable (superior a $30^{\circ}$ ) y la vegetación arbórea está ausente. En consecuencia, a pesar de no tener la orientación favorable, todos los demás factores favorecen la posibilidad de que se desencadenen aludes de placa.

Las áreas con riesgo moderado son aquellas en las que la pendiente es superior a $30^{\circ}$ y sin cobertura boscosa, pero donde el relieve no favorece grandes acumulaciones de nieve o que no está a sotavento de los vientos dominantes. Coinciden con las partes bajas de las laderas orientales, las incisiones torrenciales de ambas vertientes y el fondo de la hoya situada al norte del Macizo.

Las áreas con riesgo bajo son aquellas con pendientes pequeñas, en general los fondos de los circos glaciares, o las que, a pesar de tener pendientes elevadas presentan una densa vegetación boscosa que impide la formación de placas de nieve y el desencadenamiento de aludes. 


\subsection{Aludes de fusión}

En la figura 17 aparecen las áreas favorables al desencadenamiento de aludes de fusión en el Macizo de Peñalara.

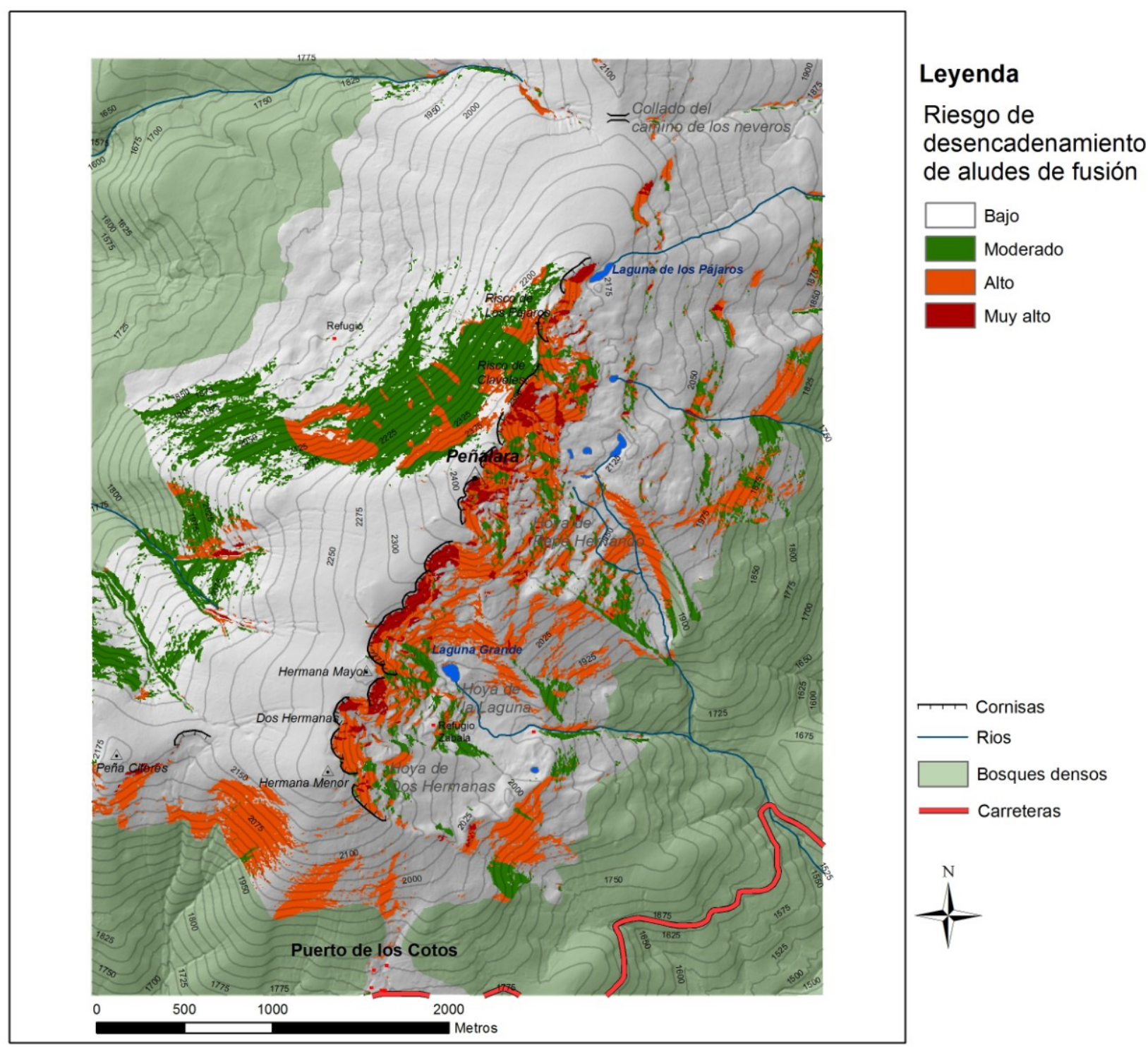

Figura 17: Mapa de áreas favorables al desencadenamiento de aludes de fusión en el Macizo de Peñalara. Elaboración propia.

Los aludes de fusión requieren mantos nivosos compuestos total o parcialmente por nieve húmeda (grano redondo). El riesgo de desencadenamiento está directamente relacionado con la presencia de agua líquida. Cuando son importantes pueden arrastrar todo el espesor del manto y producir un tipo particular de alud de fusión llamado alud de fondo. Los aludes de fondo son los que tienen más capacidad erosiva, se adaptan a la topografía del terreno y sus velocidades son relativamente lentas, ya que pocas veces superan los $20 \mathrm{~km} / \mathrm{h}$. Estos aludes, a menudo, siguen recorridos bien 
localizados y conocidos porque dependen esencialmente de la topografía. Sin embargo, vertientes enteras pueden estar afectadas por este tipo de aludes, en particular, ciertas zonas herbáceas son pendientes privilegiadas para su desencadenamiento. La frecuencia de los desencadenamientos impide que vuelva a surgir la vegetación en su trayecto y, con mucha frecuencia, dejan la roca al desnudo. La presión ejercida sobre los obstáculos encontrados durante el recorrido representa decenas de toneladas por metro cuadrado. Se explica así el arranque y movilización de bloques de rocas o de árboles.

Transportan al fondo de los valles enormes cantidades de nieve, a veces, asociadas a toda clase de materiales arrancados en el trayecto. La zona de depósito está constituida por bloques informes, de densidad importante (hasta $500-600 \mathrm{~kg} / \mathrm{m}^{3}$ ), que se amontonan en un cono de alud de varios metros de altura. Esta nieve puede persistir largo tiempo en el valle, incluso hasta que en los alrededores la vegetación ya ha tomado los colores estivales.

En el Macizo de Peñalara se han observado aludes de fusión pequeños y, con menor frecuencia, medianos. En todos los casos estos aludes son de superficie, y no se han observado aludes de fusión de fondo (figura 18).

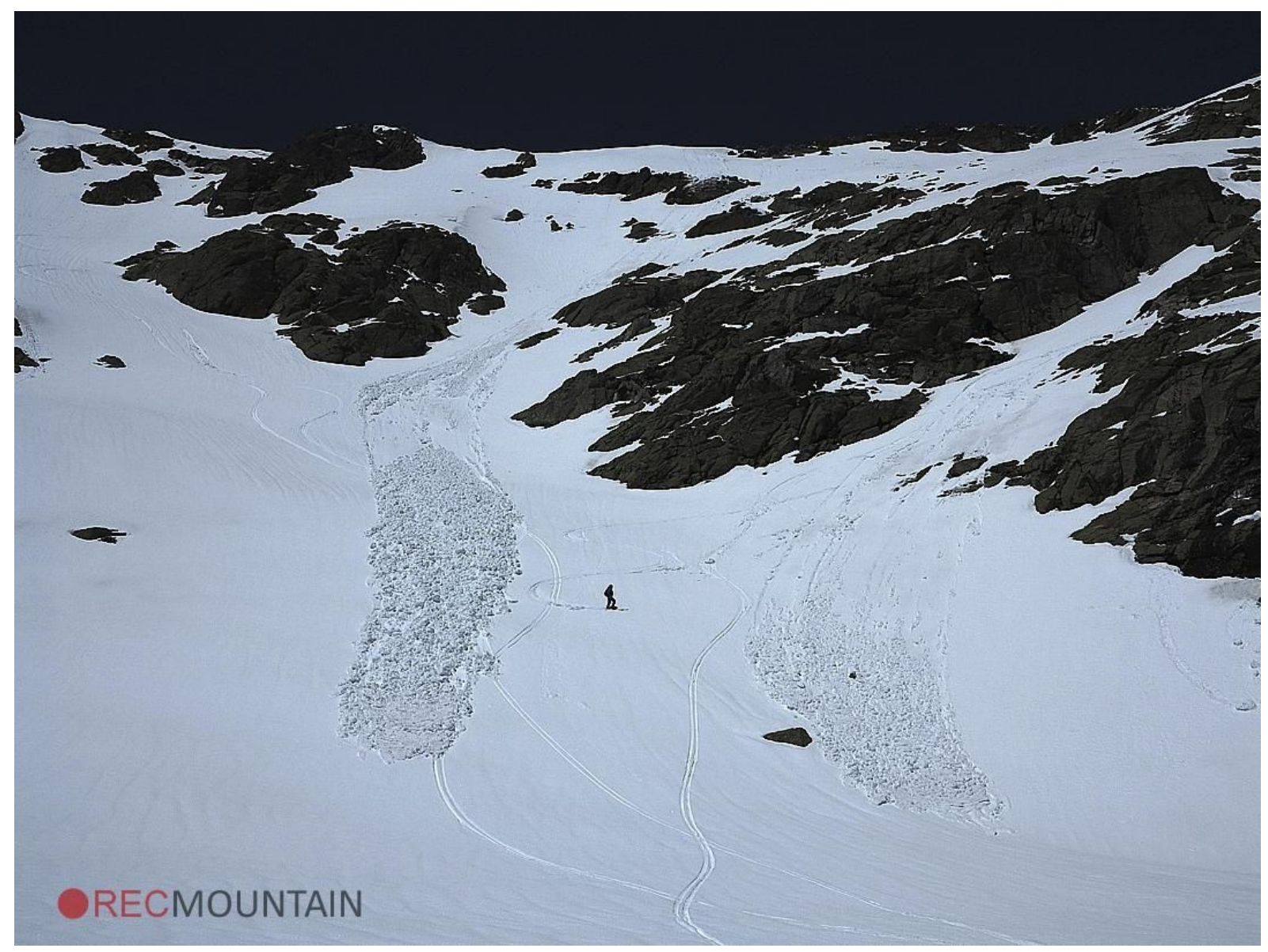

Figura 18: Ejemplo de alud de fusión. Autor: Luis Pantoja. 
El riesgo muy alto de desencadenamiento de aludes de fusión se localiza en las áreas con pendientes superiores a $25^{\circ}$, sin vegetación boscosa densa, con zonas propicias a grandes acumulaciones de nieve y elevada insolación. Estos factores confluyen en las zonas más elevadas de las cabeceras de los circos glaciares, sobre todo en las del circo de la Laguna y Claveles y en la pared de la laguna de Los Pájaros.

El riesgo alto se localiza en el resto de las cabeceras de los circos glaciares y en las laderas de las morrenas que registran mayor insolación. También presentan un riesgo alto sectores de la hoya con orientación norte ubicada al norte del Macizo y en la cabecera del arroyo del Infierno, situada entre Peña Citores y Hermana Menor, que es una zona con elevada insolación.

Las áreas con un riesgo moderado de desencadenamiento de aludes de fusión ocupan la mayor parte de la hoya situada al noroeste del Macizo, en las que la acumulación de nieve es elevada y persistente, y las laderas de las incisiones torrenciales de la vertiente oeste de éste. 


\subsection{Aludes de nieve reciente}

En la figura 19 aparecen las áreas del Macizo de Peñalara favorables al desencadenamiento de aludes de nieve reciente.

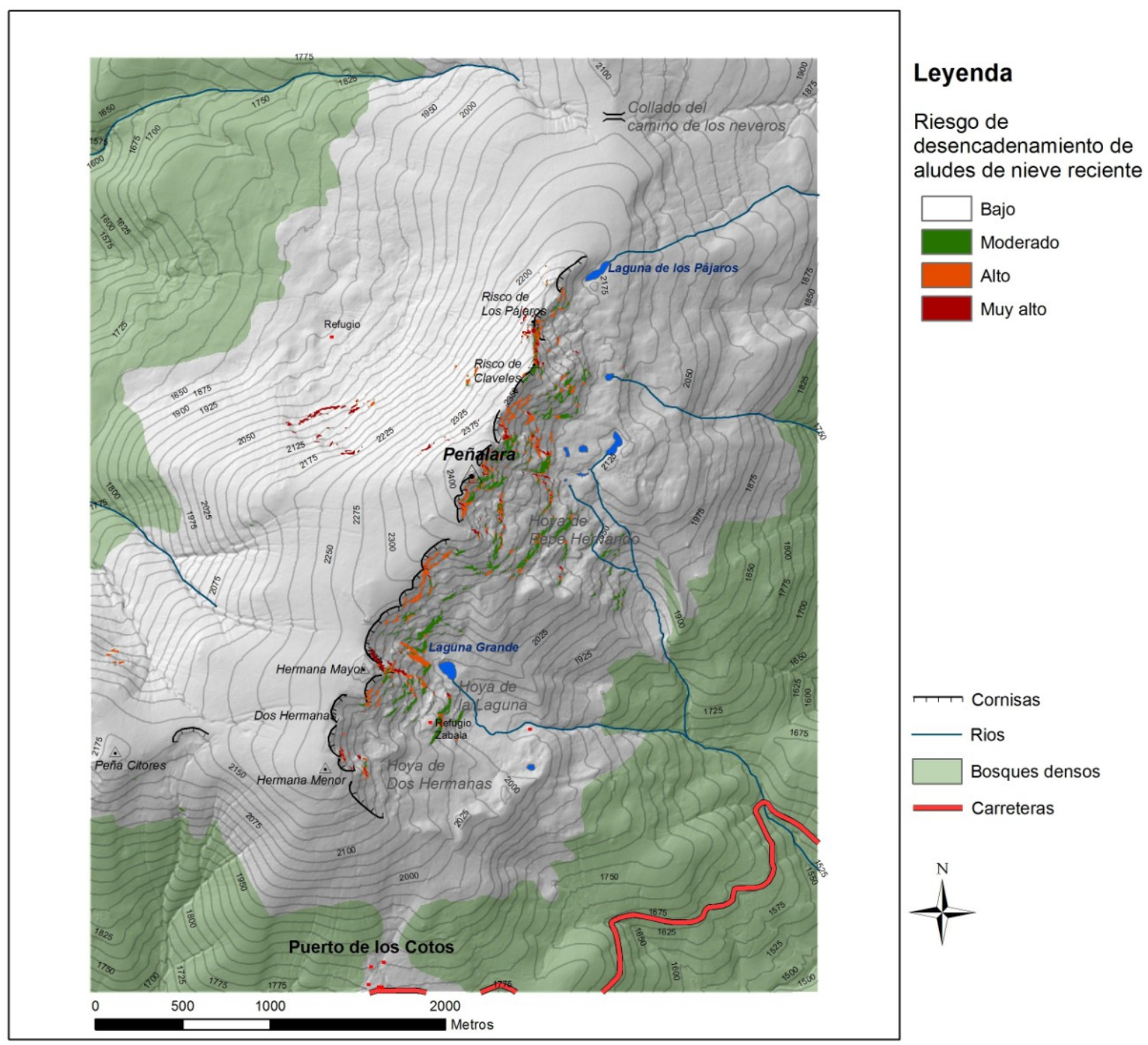

Figura 19: Mapa de áreas favorables al desencadenamiento de aludes de nieve reciente en el Macizo de Peñalara. Elaboración propia.

Los aludes de nieve reciente suelen tener salida puntual y su desencadenamiento es, en la mayoría de los casos, espontáneo. Están muy relacionados con las precipitaciones y su intensidad, humectación de la nieve reciente, temperatura del aire en el momento de la nevada y con la calidad del anclaje inferior. Dependiendo de la calidad de la nieve, y en concreto de la cantidad de agua líquida, los aludes de nieve reciente se pueden calificar como de nieve reciente húmeda o de nieve reciente seca (nieve polvo). 
Los aludes de nieve reciente polvo pueden llegar a ser muy espectaculares. Se desencadenan cuando coinciden ciertas condiciones: nieve ligera, densidad generalmente inferior a $100 \mathrm{~kg} / \mathrm{m}^{3}$ y ángulo y longitud de pendiente suficientes. Estas características se asocian a la nieve caída con temperaturas frías (sobre las vertientes norte, el peligro de desencadenamiento de aludes de nieve polvo puede persistir varios días).

En el Macizo de Peñalara los aludes de nieve reciente son poco frecuentes, pero se han registrado en alguna ocasión. El episodio más reciente se produjo en el mes de enero de 2009 cuando un alud de nieve reciente seca provocado por la ruptura de una placa friable, pasó por encima del Refugio de Zabala sin provocar ningún daño apreciable pero sí algún accidentado (figura 20).

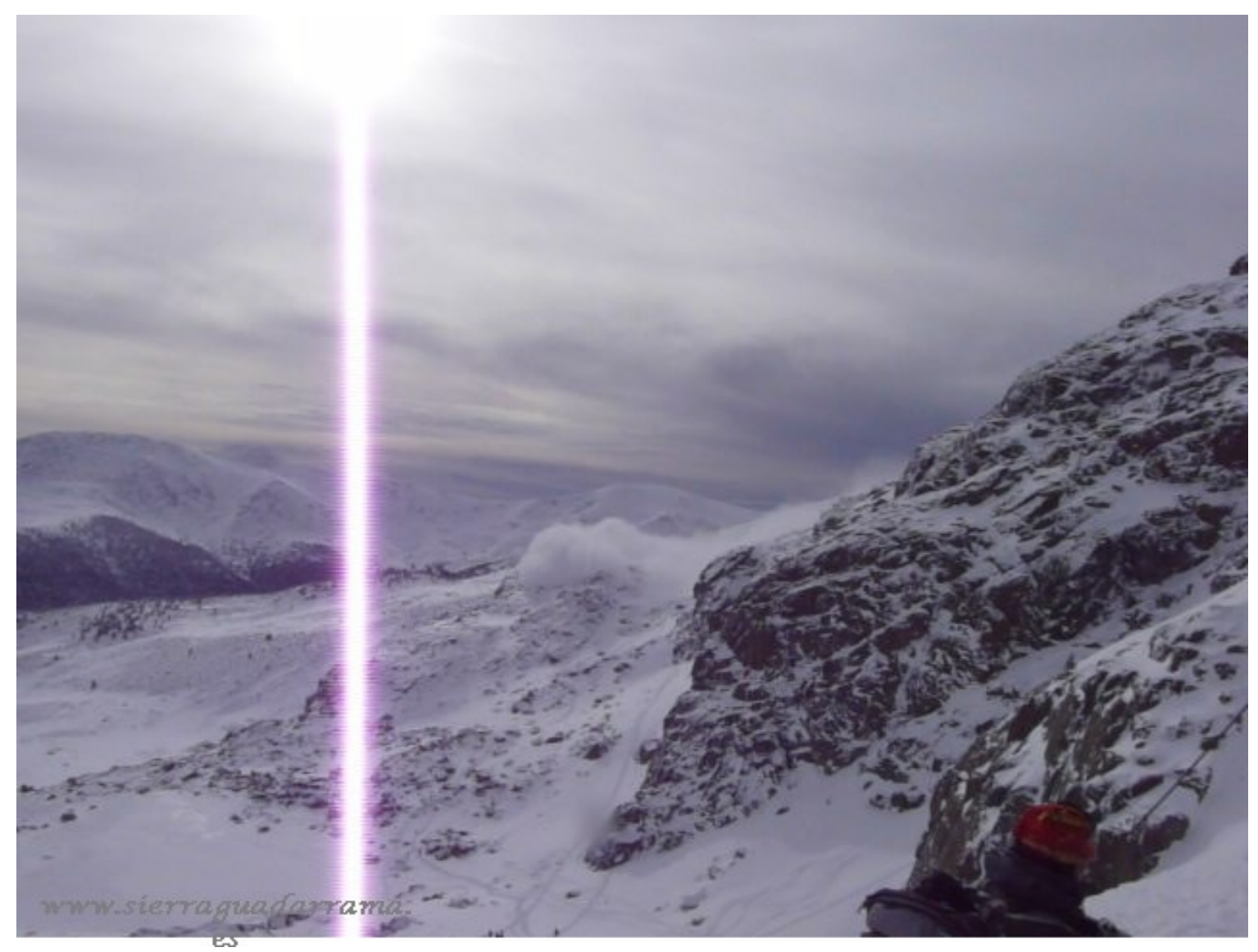

Figura 20: Ejemplo de alud de nieve polvo por rotura de placa friable sobre el refugio de Zabala. Enero 2009. Fuente: http://www.sierraguadarrama.es. (fuera de servicio)

Como se observa en la figura 19, las zonas favorables al desencadenamiento de aludes de nieve reciente en el Macizo de Peñalara son escasas. En términos generales los riesgos muy altos y altos de desencadenamiento de este tipo de aludes se localizan en las zonas más próximas a las crestas 
vertientes orientales del Macizo ya que son las únicas que presentan elevadas pendientes (superiores a $45^{\circ}$ ).

El riesgo moderado se restringe a las zonas de elevada pendiente, pero con altitud inferior, y que acumulan poca insolación (pendiente superior a $45^{\circ}$, ausencia de bosques, zonas con insolación baja). 


\subsection{Cartografía general de riesgo de aludes.}

La figura 21 muestra, para el Macizo de Peñalara, las áreas favorables al desencadenamiento de cualquier tipo de alud. Esta cartografía se ha obtenido aplicando la metodología expuesta en la figura 11.

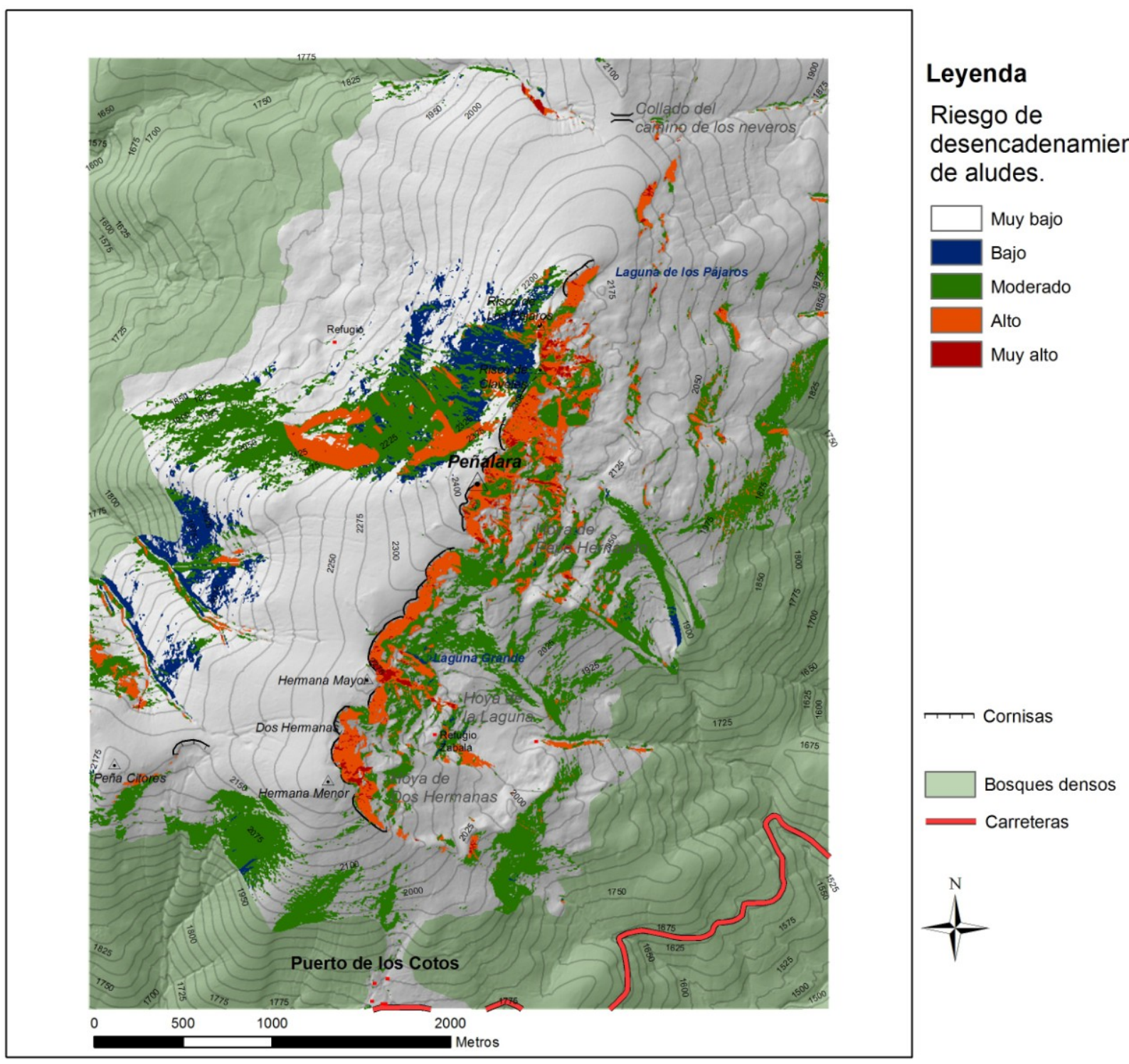

Figura 21: Mapa de áreas favorables al desencadenamiento de aludes en el Macizo de Peñalara. Elaboración propia.

En la figura 21 se observa que, en el Macizo, las áreas más propicias al desencadenamiento de aludes (categorías 3 y 4 ) se localizan en las cotas más altas de las vertientes orientales, las que presentan mayor pendiente y acumulación de nieve. En la hoya localizada en el extremo norte del Macizo también existe una amplia área favorable al desencadenamiento, debido a que presenta acumulaciones de nieve importantes y persistentes y pendientes suficientes. 
En las zonas con menor acumulación de nieve, pero que presentan una pendiente suficiente y una vegetación favorable, como son las partes menos elevadas de las paredes glaciares y las vertientes orientales de las morrenas, la probabilidad de ocurrencia de aludes es menor, aunque no despreciable (categoría 2). Finalmente, los sectores incluidos en la categoría 1 corresponden a las áreas con pendientes propicias, superiores a $25^{\circ}$, y sin bosques densos pero que no presentan más factores propicios. Estas zonas se limitan al extremo septentrional de la hoya situada al norte del Macizo y a las incisiones torrenciales que aparecen en las laderas occidentales de éste.

En la figura 22 se han cartografiado también las zonas favorables al desencadenamiento de aludes obtenidas según los criterios nivológicos y geomorfológicos definidos en la Escala de Clasificación del Terreno favorable al desencadenamiento de avalanchas (Avalanche Terrain Exposure Scale, ATES) (Ver figura 11). Según estos criterios para la clasificación del terreno en función de los aludes, se han delimitado tres áreas que corresponden a las tres categorías de esta escala (Simple, Desafiante y Complejo). 


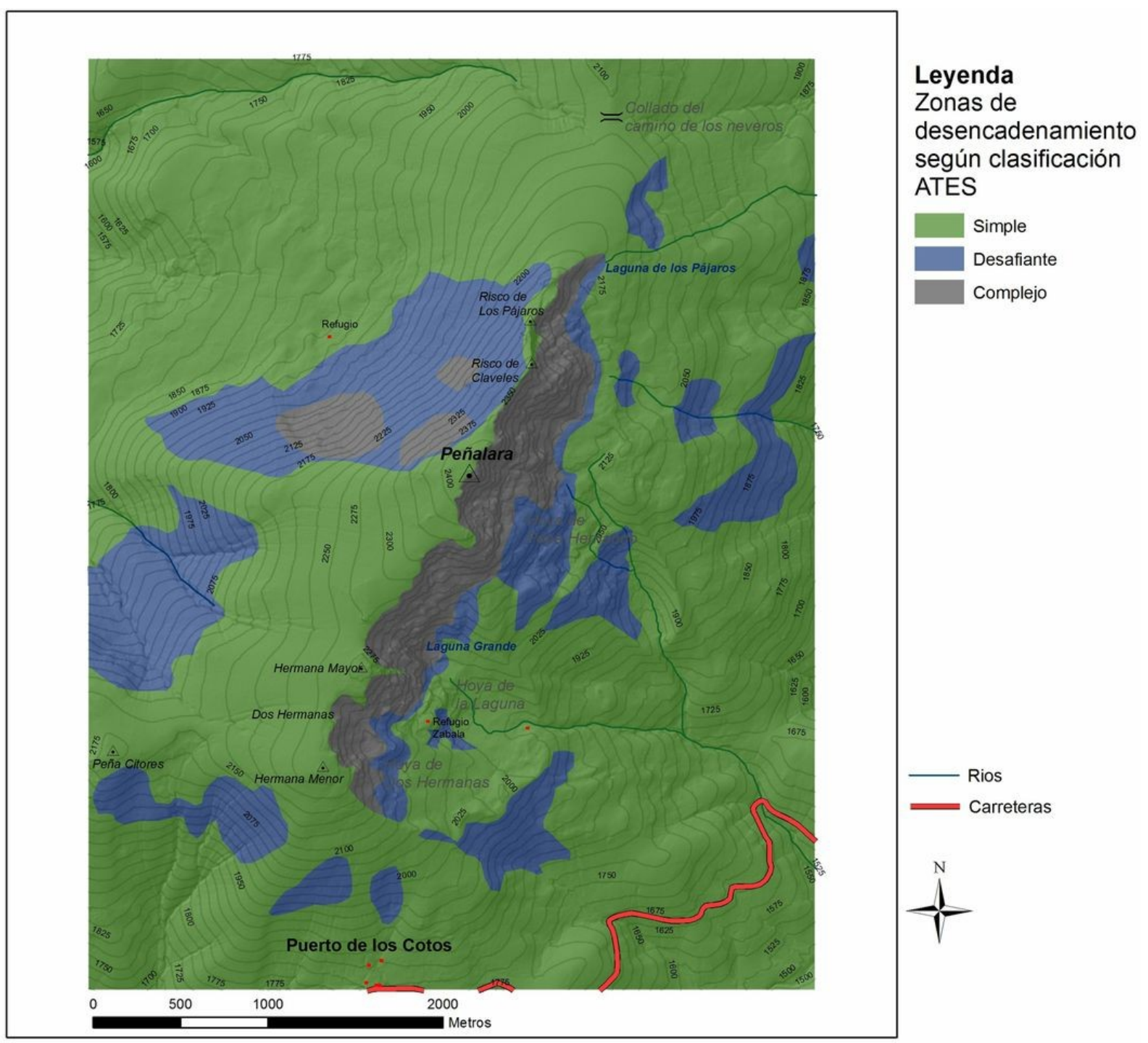

Figura 22: Mapa de áreas favorables al desencadenamiento de aludes en el Macizo de Peñalara según criterios ATES. Elaboración propia.

Una vez que hemos delimitado las tres categorías de la ATES, se han superpuesto una capa con dicha clasificación de la ATES (figura 22) y otra con la zona de riesgo de aludes obtenida anteriormente (figura 21). El resultado aparece en la figura 23. 


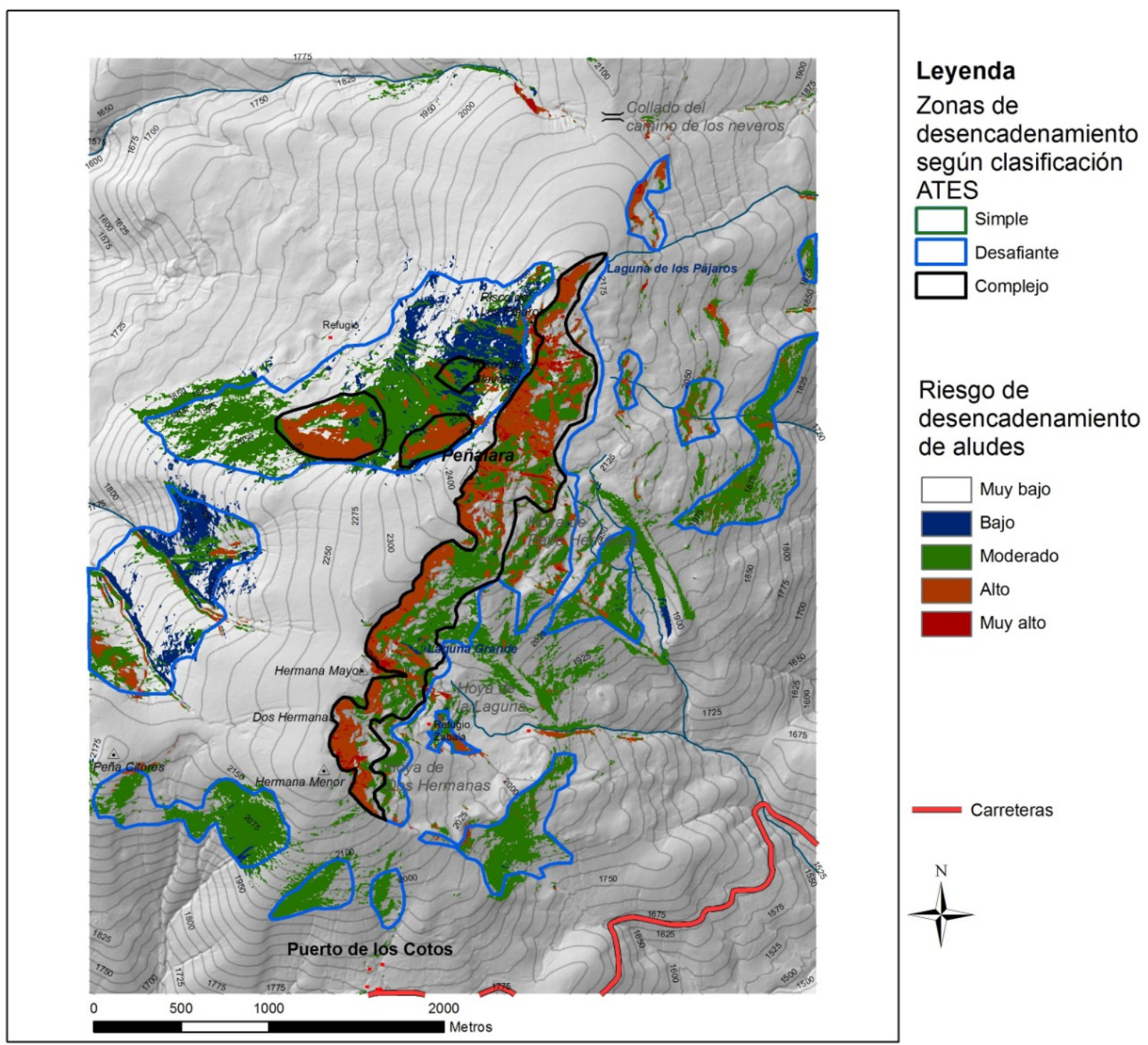

Figura 23: Mapa de áreas favorables al desencadenamiento de aludes en el Macizo de Peñalara según los criterios ATES y según los establecidos en el trabajo. Elaboración propia.

Como puede observarse en la figura 23, la mayoría de las zonas incluidas en las categorías 3 y 4 , se corresponden con las áreas clasificadas como terreno Complejo según la clasificación ATES. Existe una pequeña discrepancia en la parte media-alta de la hoya de Pepe Hernando. Esta zona se ha clasificado como terreno Desafiante y no como Complejo porque existen numerosas depresiones de sobre-excavación y escalones y umbrales entre ellas que tienden a romper la pendiente y frenar los posibles aludes. Igualmente la morrena derecha de la misma hoya de Pepe Hernando se ha clasificado como Desafiante debido a que tiene un bosque en la parte alta de la morrena y a que es una zona muy poco propensa a la acumulación de nieve y a la formación de placas. Algo parecido a esto último ocurre alrededor de la morrena oriental del circo de la Laguna Grande. 
También se puede apreciar como la mayoría de las zonas correspondientes a las categorías 1 y 2 están dentro del terreno clasificado como Desafiante.

\section{6.- CONCLUSIONES.}

Los aludes suponen uno de los riesgos naturales más importantes que afectan a las áreas de montaña. En España los aludes se presentan de manera habitual en la Cordillera Pirenaíca, aunque esto no significa que en el resto de los sistemas montañosos peninsulares no se produzcan, pero sí que su ocurrencia es más irregular y su tamaño generalmente menor.

En el Macizo de Peñalara la nieve se caracteriza por su gran variabilidad inter e intra anual, como corresponde a un clima mediterráneo continentalizado de montaña. Así, se suceden inviernos, como el de la temporada 2011-2012, muy escasos en nieve, y por el contrario inviernos con abundantes nevadas, como el 1990-1991. La variabilidad inter anual se puede comprobar en el invierno 20122013 que fue muy poco nivoso hasta principios de enero y muy nivoso desde mediados de enero hasta bien entrada la primavera. Esta irregularidad en la presencia de nieve en el Macizo se traslada a la frecuencia de desencadenamiento de aludes en él.

Los aludes en el Macizo de Peñalara tan sólo se producen en las zonas más altas, por encima de $1900 \mathrm{~m}$, por lo que no afectan a las construcciones ni a las infraestructuras. De todas formas, el número muy importante y creciente de personas que visitan el Macizo y se adentran incluso en las zonas potencialmente más peligrosas hacen que la probabilidad de encuentro alud - persona sea elevada. Con la nueva figura de protección que afecta a la zona de estudio, sería oportuno incorporar al Plan Rector de Uso y Gestión del Parque Nacional información sobre las zonas más expuestas a los aludes.

Los aludes que se producen más frecuentemente en el Macizo son los aludes de placa, siendo también los que más accidentes provocan. Este tipo de aludes se desencadenan preferentemente en las laderas del Macizo con orientación este, debido a que estas vertientes son las más propicias a la formación de placas. La mayor parte de las placas se forman a sotavento de los vientos dominantes, en las zonas inmediatamente inferiores a las líneas de cumbres. En muchos casos están acompañadas de cornisas de nieve. Los aludes de placa pueden producirse en cualquier momento del invierno y no están necesariamente ligados a una situación meteorológica determinada porque las placas pueden persistir durante largo tiempo.

Los aludes de fusión tienden a producirse en primavera, pero también se han observado en otros periodos del invierno coincidiendo con una temporada de temperaturas altas. Suelen ser coladas, aludes pequeños o medianos, y en ningún caso, se han visto aludes de fondo. 
Los aludes de nieve reciente se producen tras un periodo de nevadas intensas. En el Macizo de Peñalara se han observado, de forma esporádica, aludes de placa friable que evolucionan a aludes de nieve reciente polvo.

Es necesario continuar aumentando el contenido de la base de datos de registros nivológicos, para comprobar la validez del mapa de riesgo de aludes que se ha realizado o modificarlo sí es necesario. En este sentido, sería conveniente, ampliar las observaciones a otras áreas de la Sierra de Guadarrama y Somosierra. 


\section{BIBLIOGRAFÍA}

- Alía, M., Menéndez, J. y Vidal, C. (1957). Livret-Guide de l'excursion C3 et C4 Guadarrama, Massif de Peñalara et variation El Escorial-Manzanares el Real. Actas V Congreso Internacional INQUA. pp: 28-34. Madrid.

- Andrés, N. y Palacios, D. (2004). Interrelación Nieve / Geomorfología en la Sierra de Guadarrama: altas cuencas del Ventisquero de la Condesa y Valdemartín. Cuadernos de Investigación Geográfica n³0. pp: 83-113.

- Andrés, N. y Palacios, D. (2005). Relación entre dinámica nival y erosión en el Parque Natural de Peñalara y áreas próximas. Quintas Jornadas Científicas del Parque Natural de Peñalara y del Valle del Paular. pp: 95-138. El Paular, Rascafría (Madrid).

- Andrés, N., García, A., Muñoz, J. y Palacios, D. (2007). Control of snow cover duration in geomorphologic and biogeographic dynamics in Mediterranean mountains: Manzanares valley head, Sierra de Guadarrama (Spain). Zeitschrift für Geomorphologie n51(2). pp: 91-111.

- Asensio, I. y Ontañón, J. M. (1972). Acumulaciones periglaciares en el Valle de las Guarramillas (vertiente septentrional de la Sierra de Guadarrama). Estudios Geológicos n²8 (6). pp: 453-462.

- Asensio, I. y Ontañón, J. M. (1975). Evolución de surcos de escorrentía sobre vertientes periglaciares. Estudios Geológicos n³1. pp: 625-627.

- Bullón, T. (1977). Los fenómenos periglaciares de la Sierra de la Mujer Muerta (Sierra de Guadarrama). V Coloquio de Geografía. Granada. pp: 35-40.

- Bullón, T. (1988). El Guadarrama Occidental. Comunidad de Madrid, Madrid.

- Bullón, T. (1995). Hillslope erosion, environmental changes and land management on a Spanish mountain. Physics and Chemistry of Earth n²0 (3/4). pp: 339-344.

- Campbell, C. y Marshall, P. (2010). Mapping exposure to avalanche terrain. Canadian Avalanche Center. Anchorage, Alaska

- Coleou, C., Giraud, G. y Villecrose, J. (1993). Análisis de los sondeos por golpeo. Traducción del CMT de Aragón, La Rioja y Navarra (INM). Francia. Météo-France. CNRM CEN.

- Fernández-González, F. (1988). Estudio florístico y fitosociológico del Valle del Paular (Madrid). Tesis doctoral sin publicar, Facultad de Biología, Universidad Complutense, Madrid.

- Fernández-González, F. (1991). La vegetación del Valle del Paular (Sierra de Guadarrama, Madrid), I. Lazaroa n¹2. pp: 153-272.

- Fernández-González, F. (1999). La flora y la vegetación del Parque Natural de Peñalara y del Valle del Paular (Madrid): implicaciones en la conservación de la biodiversidad. Primeros encuentros científicos del Parque Natural de Peñalara y del Valle del Paular. pp: 179-196. Comunidad de Madrid.

- Franzle, O. (1959). Glaziale und periglaziale Formbildung im östlichen kastilischen scheidegebirge (Zentral-spaninen). Bonner Geographische Abhandlungen, Bonn. 
- Furdada, G. (1996). Estudi de les allaus al Pirineu Occidental de Catalunya: predicció espacial i aplicaciones de la cartografía. Ed. Geoforma ediciones. Logroño.

- Gavilán, R., Fernández González, F. y Blasic, C. (1998). Climatic classification and ordination of the Spanish Sistema Central: relationships with potential vegetation. Plant Ecology n¹39. pp: 1 11.

- Guyomarc'h, G. (1996). Les avalanches. Traducción del CMT de Aragón, La Rioja y Navarra (INM). Francia. Météo-France. CNRM CEN.

- Julián, A. y Chueca, J. (1999). Cartografía de zonas probables de aludes en el valle de Ordesa (Pirineo Aragonés). Geographicalia, 37: 73-86.

- Julián, A. y Chueca, J. (2010). Cartografía de zonas probables de salida de aludes en el Alto Gállego (Pirineo Central Aragonés) mediante el empleo de Sistemas de Información Geográfica. Cuadernos de Investigación Geográfica 36. Pp 27-41.

- Julián, A., Peña, J.L., Chueca, J., Zabalza, J., Lapeña, A. y López, I. (2000): Cartografía de zonas probables de aludes en el Pirineo Aragonés: Metodología y resultados. Boletín de la A.G.E., 30, pgs. 119 - 134.

- Luceño, M. y Vargas, P. (1991). Guía botánica del Sistema Central español, Ed. Pirámide. Madrid.

- Marcos, J. y Palacios, D. (2004). Efectos de la nieve y la temperatura del suelo en la actividad geomorfológica: primeros resultados de su monitorización en la Sierra de Guadarrama (España). Boletín de la Real Sociedad Española de Historia Natural (Sección Geología) n99 (1-4). pp: 2536.

- Muñoz Trigo, P. (1988). Prevención y defensa contra aludes. Aplicación práctica al Pirineo aragonés. Tesis doctoral Universidad Politécnica de Madrid (Escuela de Montes).

- Muñoz, J. y García, A. (2004). Modificaciones climáticas y evolución de la cubierta vegetal en las áreas culminantes de la Sierra de Guadarrama (Sistema Central Español) durante la segunda mitad del siglo XX: las altas cuencas del Ventisquero de la Condesa y Valdemartín. Cuadernos de Investigación Geográfica n³0. pp: 117-146.

- Muñoz, J., Palacios, D. y Marcos, J. (1995). The influence of the geomorphologic heritage on present slope dynamics. The Gredos Cirque, Spain. Pirineos n¹45-146. pp: 35-63.

- Obermaier, H. y Carandell, J. (1917). Los glaciares cuaternarios de la Sierra de Guadarrama, Trabajos del Museo Nacional de Ciencias Naturales n¹9. pp: 1-92.

- Palacios, D. y García, M. (1997a). The influence of geomorphologic heritage on present nival erosion: Peñalara, Spain. Geografisca Annaler n79. pp: 25-40.

- Palacios, D. y García, M. (1997b). The Distribution of High Mountain Vegetation in relation to snow cover: Peñalara, Spain. Catena $n^{\circ} 30 . p p:$ 1-40.

- Palacios, D. y Andrés, N. (2000). Morfodinámica supraforestal actual en la Sierra de Guadarrama y su relación con la cubierta nival: el caso de Dos Hermanas- Peñalara. En: Procesos y formas 
periglaciares en la montaña mediterránea. J.L. Peña, M. Sánchez-Fabre, Lozano, M.V. Eds. pp: 235-264. Instituto de Estudios Turolenses, Teruel.

- Palacios, D. y Andrés, N. (2005). Relación entre dinámica nival y erosión en el Parque Natural de Peñalara y áreas próximas. Quintos encuentros científicos del Parque Natural de Peñalara y del Valle del Paular. pp: 95-137. El Paular, Rascafría (Madrid).

- Palacios, D., Andrés, N. y Luengo, E. (2003). Distribution and effectiveness of nivation in Mediterranean mountains: Peñalara (Spain). Geomorphology, n54. pp: 157-178.

- Palacios, D., Andrés, N. y Luengo, E. (2004). Tipología y evolución de nichos de nivación en la Sierra de Guadarrama, España. Boletín de la Real Sociedad Española de Historia Natural (Sección Geología) n99 (1-4). pp: 141-158.

- Palomo, M. (2007). Los aludes en el circo de Piedrafita (Pirineo Aragonés). El evento del 8 de febrero de 1996. Boletín Glaciológico Aragonés, pp: 8:61-83.

- Palomo, M. (2012). Temperatura del suelo en las cumbres de la Sierra de Guadarrama. Tesis D.E.A. Universidad Complutense de Madrid.

- Palomo, M., Julián, A. y Chueca, J. (2008). Aplicación de un análisis multicriterio a la delimitación de zonas probables de aludes (valle del Aguas Limpias, Pirineo central español). En Benavente, J. Y Gracia, F.J. (Eds.): Trabajos de Geomorfología en España, 2006-2008. Sociedad Española de Geomorfología, pp: 417-420. Cádiz.

- Pedraza, J., Carrasco, R.M., Martín-Duque, J.F. y Sanz, M.A. (2004). El Macizo de Peñalara (Sistema Central Español). Morfoestructura y modelado. Boletín de la Real Sociedad Española de Historia Natural (Sección Geología) n99 (1-4). pp: 185-196.

- Rey, L. (1985). La nieve, su metamorfosis. Los aludes. MOPT. Madrid

- Rivas-Martínez, S. (1963). Estudio de la Vegetación y Flora de las Sierras de Guadarrama y Gredos. Anales del Instituto Botánico Cavanilles nº 21 (1). pp: 5-325.

- Rivas-Martínez, S. (1982). Mapa de las series de vegetación de la provincia de Madrid. Escala 1:200.000. Publicaciones del Servicio Forestal del Medio Ambiente y contra Incendios, Diputación Provincial Madrid.

- Rivas-Martínez, S., Fernández-González, F., Sánchez-Mata, D. y Pizarro, J. (1990). Vegetación de la Sierra de Guadarrama. Guía geobotánica de la Excursión de las II Jornadas de Taxonomía Vegetal. Itinera Geobotanica. Vol. 4. Asociación Española de Fitosociología, Madrid.

- Rivas-Martínez, S., Cantó, B.P., Fernández-González, F., Molina, J.A., Pizarro, J. y SánchezMata, D. (1999). Synopsis of the Sierra de Guadarrama Vegetation. Itinera Geobotánica nº13. pp: $189-206$.

- Sáez Alagón, M.T. (1993). Atlas de Zonas Probables de Aludes en el Valle del Aragón (dos tomos). Oficina de Proyectos del IGME de Zaragoza.

- Sáez Alagón, M.T. (1995). Atlas de Zonas Probables de Aludes en el Valle del Gállego (tres volúmenes). Oficina de Proyectos del IGME de Zaragoza. 
- Sanz, C. (1979). El Mosaico de geofacies supraorientales en la zona más elevada de la Sierra de Guadarrama. Actas del VI Coloquio de Geografía. pp: 240-247. Murcia.

- Sanz, C. (1986). Periglaciarismo en montaña: La Sierra de Guadarrama. En Atlas de Geomorfología, Alianza editorial. Madrid. pp: 239-254.

- Sanz, C. (1988). El relieve del Guadarrama oriental. Consejería de Política Territorial. Comunidad Autónoma de Madrid. Madrid.

- Santos, J., Redondo, J.M., Gómez, A. y González, R.B. (2010). Los aludes de nieve en el Alto Sil (Oeste de la Cordillera Cantábrica, España). Cuadernos de Investigación Geográfica n³6. Pp: 726.

- Statham, G. y MacMahon, B. (2004). Avalanche terrain exposure scale (v.1-04). PARKS CANADA AGENCY.

- Vada, J.A., Frochoso, M. y Vilaplana, J.M., (2012). Evaluación y cartografía del riesgo de aludes en el camino PR-PNPE 21 de acceso a la Vega de Urriellu, Picos de Europa (Noroeste de España). Cuaternario y Geomorfología.

- Zúñiga, I. y Crespo del Arco, E. (2009). Meteorología y Climatología. Unidad Didáctica. UNED. Madrid.

\section{WEBGRAFÍA}

- Canadian Avalanche Center: The Avalanche terrain exposure scale. [en línea][fecha de consulta febrero 2013]. URL: <http:/www.avalanche.ca/cac/training/onlinecourse/terrain/ATES>

- Palacios, D. y Andrés, N. (2006). El significado geográfico de la nieve en la dinámica natural de la Sierra de Guadarrama. [ en línea]. [fecha de consulta: enero 2013].

URL:https://portal.ucm.es/web/gfam/recursos. Grupo de Investigación en Geografía Física de Alta Montaña. Universidad Complutense de Madrid.

- Sanz, G., Rodríguez J., Pascual R., Pantoja, L., Fernández-Cañadas, J.A., Miquel, E. y García, J.A. (2012). Guía para la observación nivometeorológica. [en línea][consulta febrero 2013].URL:<http: //www . aemet.es/es/conocermas/publicaciones/detalles/Guia_n ivometeorologicas.

- WSL Swiss Federal Institute for Snow and Avalanche Research SLF. Using GIS for avalanche hazard mapping in Switzerland (1999) [en línea] [fecha consulta febrero 2013].

URL:<http://proceedings.esri.com/library/userconf/proc01/professional/pap ers/pap964/p964.htm>.

- Wetterzentrale [en línea] [fecha consulta enero 2013]. URL:

(http://www.wetterzentrale.de) 
ANEXO I: CARTOGRAFÍA

\section{ÁREAS CON VEGETACIÓN FORESTAL DENSA}

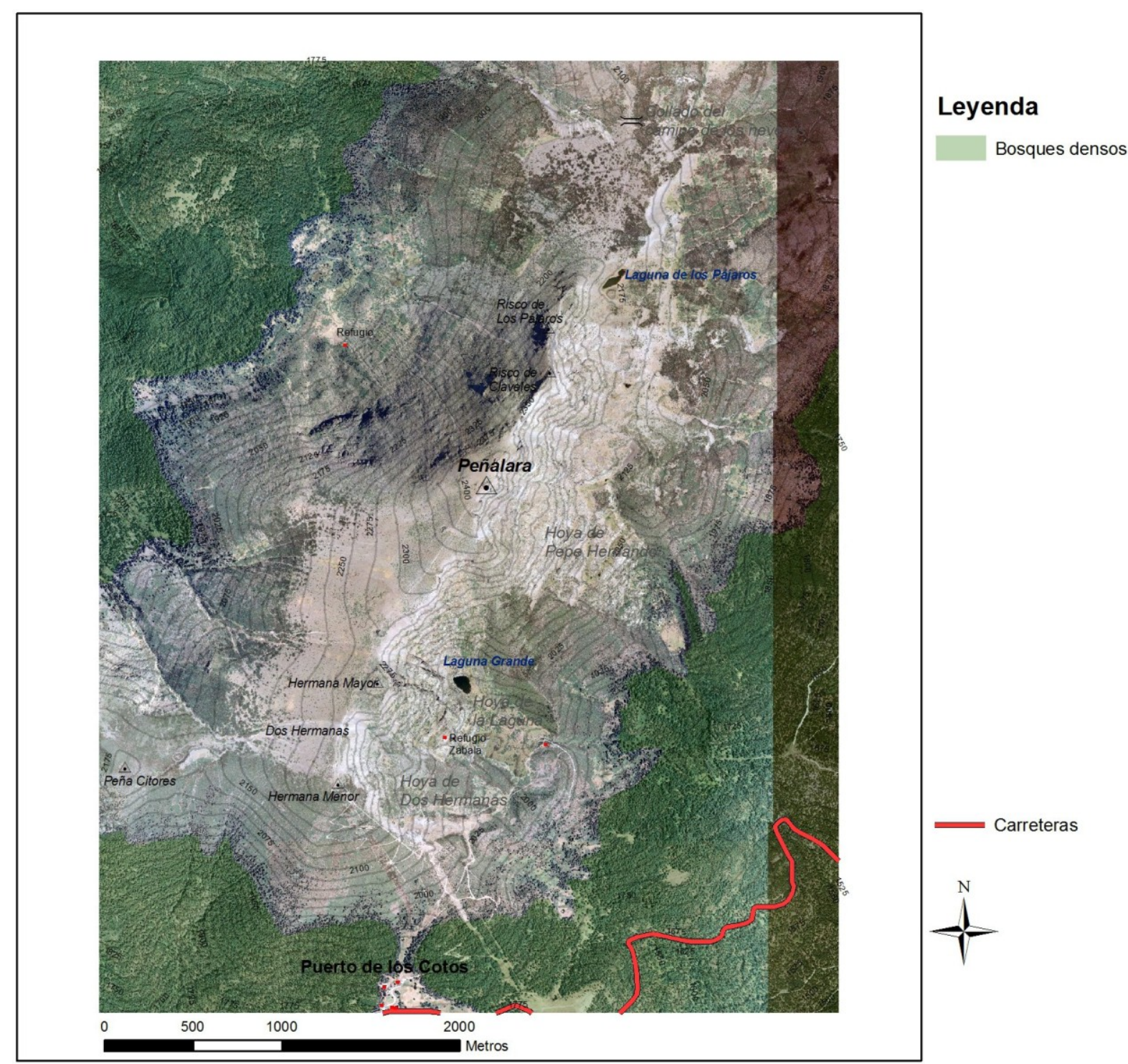

Figura a.1: Áreas con bosques densos en el Macizo de Peñalara. Datos: PNOA (IGN). Elaboración propia. 


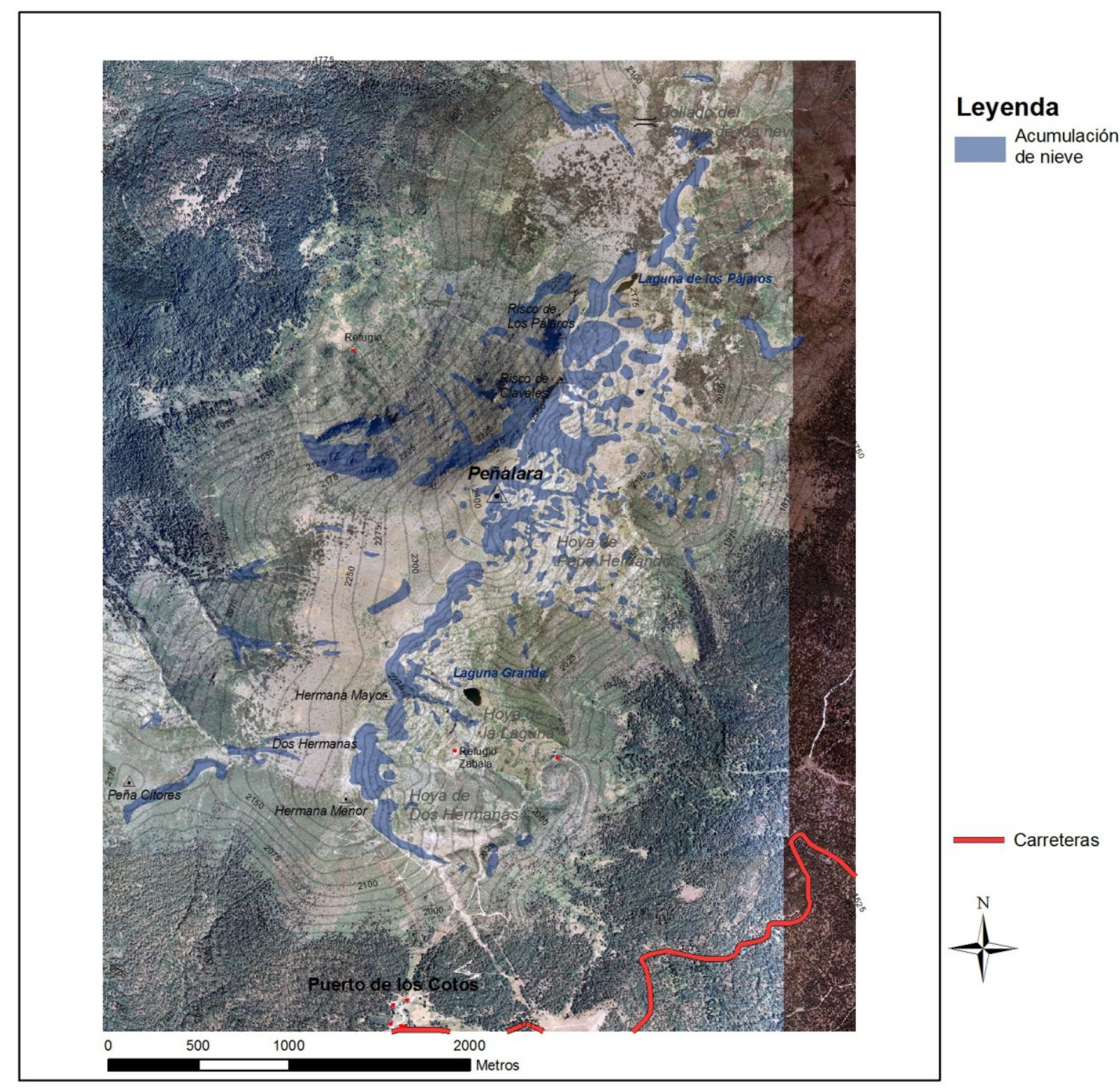

Figura a.2: Áreas de acumulación de nieve en el Macizo de Peñalara. Datos: PNOA (IGN). Elaboración propia. 


\section{ÁREAS CON PENDIENTE SUPERIOR A $25^{\circ}$}

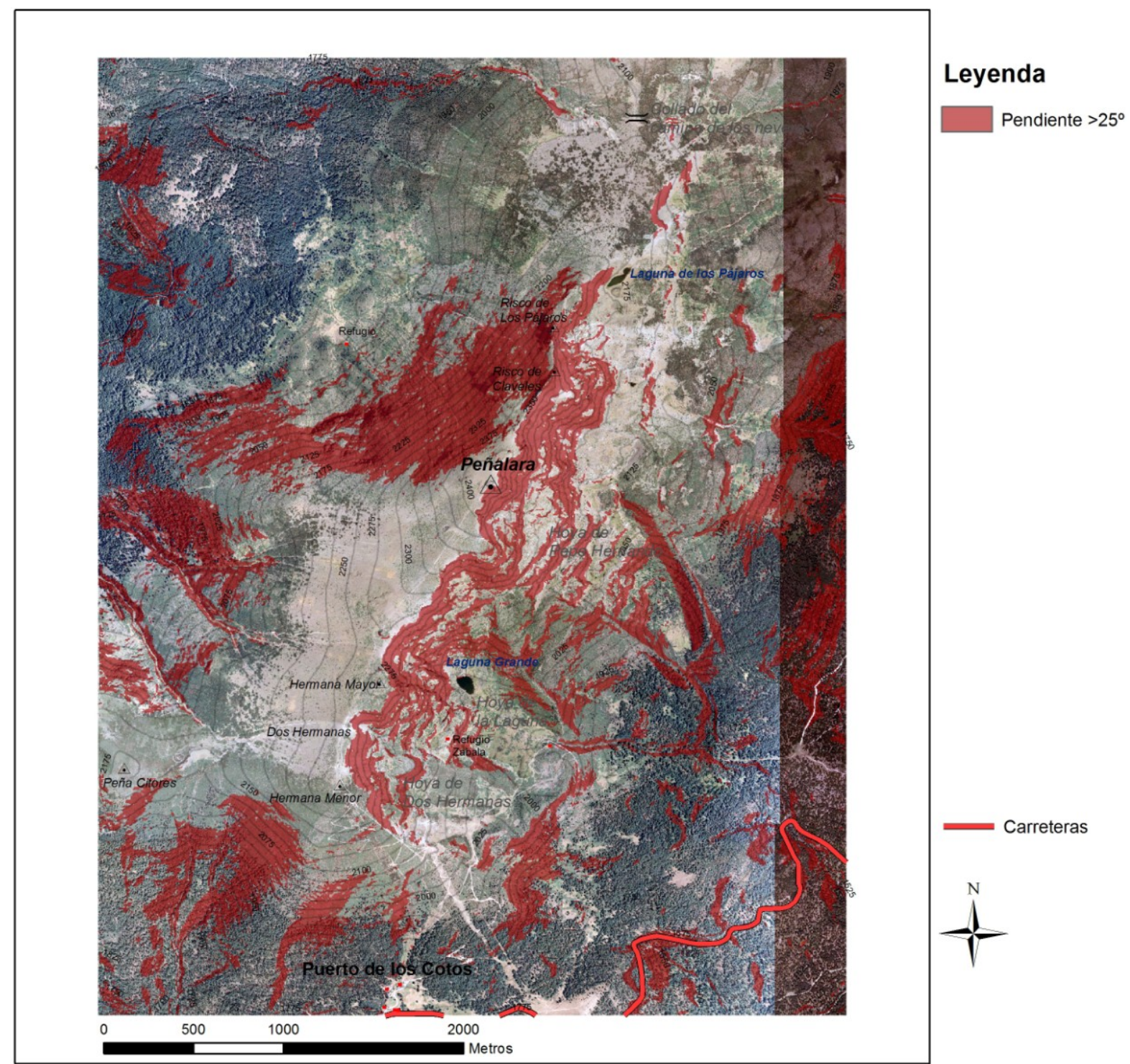

Figura a.3: Áreas con pendiente superior a $25^{\circ}$ en el Macizo de Peñalara.

Datos: PNOA (IGN). Elaboración propia. 


\section{ÁREAS CON PENDIENTE SUPERIOR A $30^{\circ}$}

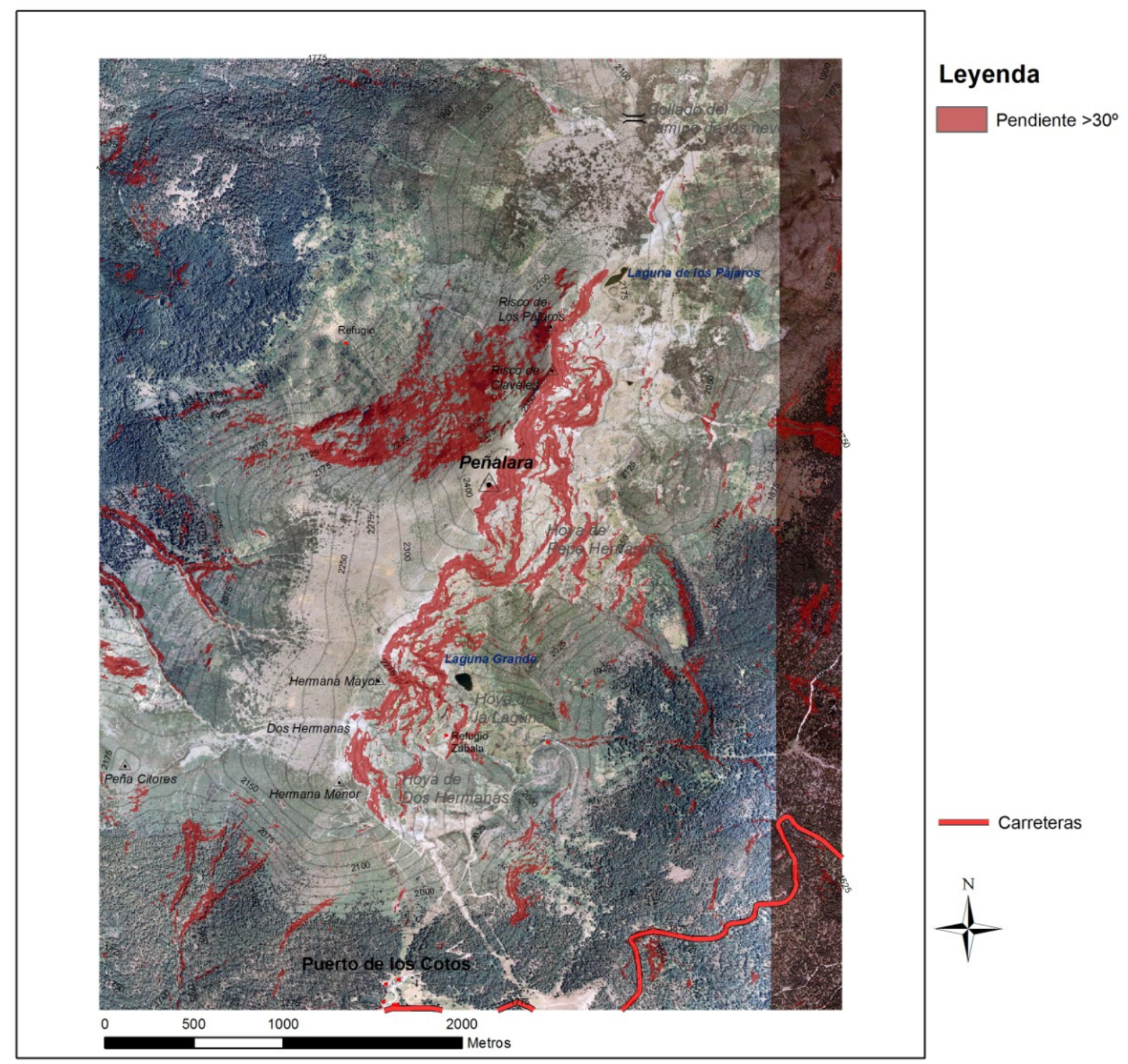

Figura a.4: Áreas con pendiente superior a $30^{\circ}$ en el Macizo de Peñalara.

Datos: PNOA (IGN). Elaboración propia. 


\section{ÁREAS CON PENDIENTE SUPERIOR A $45^{\circ}$}

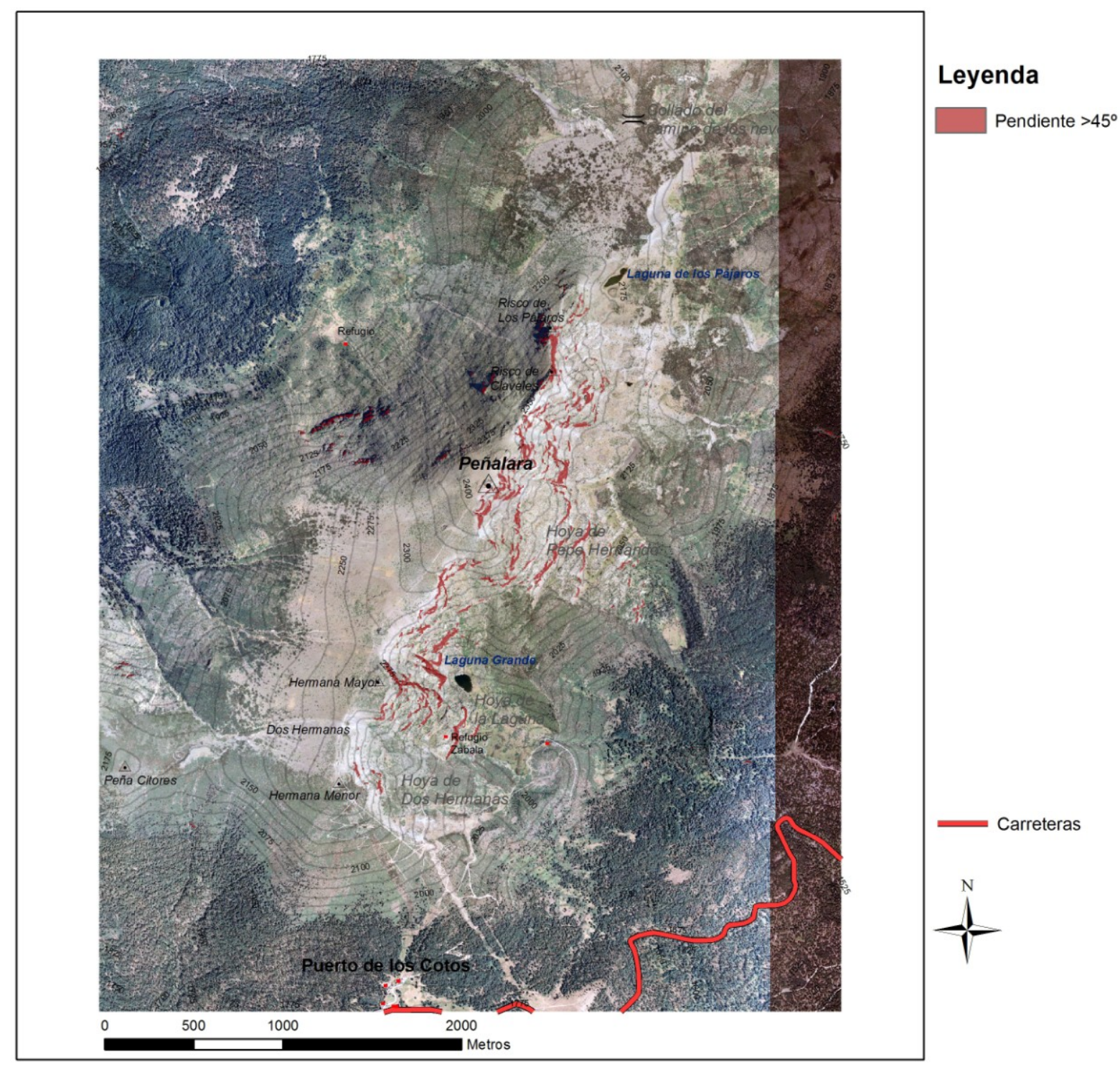

Figura a.5: Áreas con pendiente superior a $45^{\circ}$ en el Macizo de Peñalara.

Datos: PNOA (IGN). Elaboración propia. 


\section{ÁREAS CON ORIENTACIÓN ESTE}

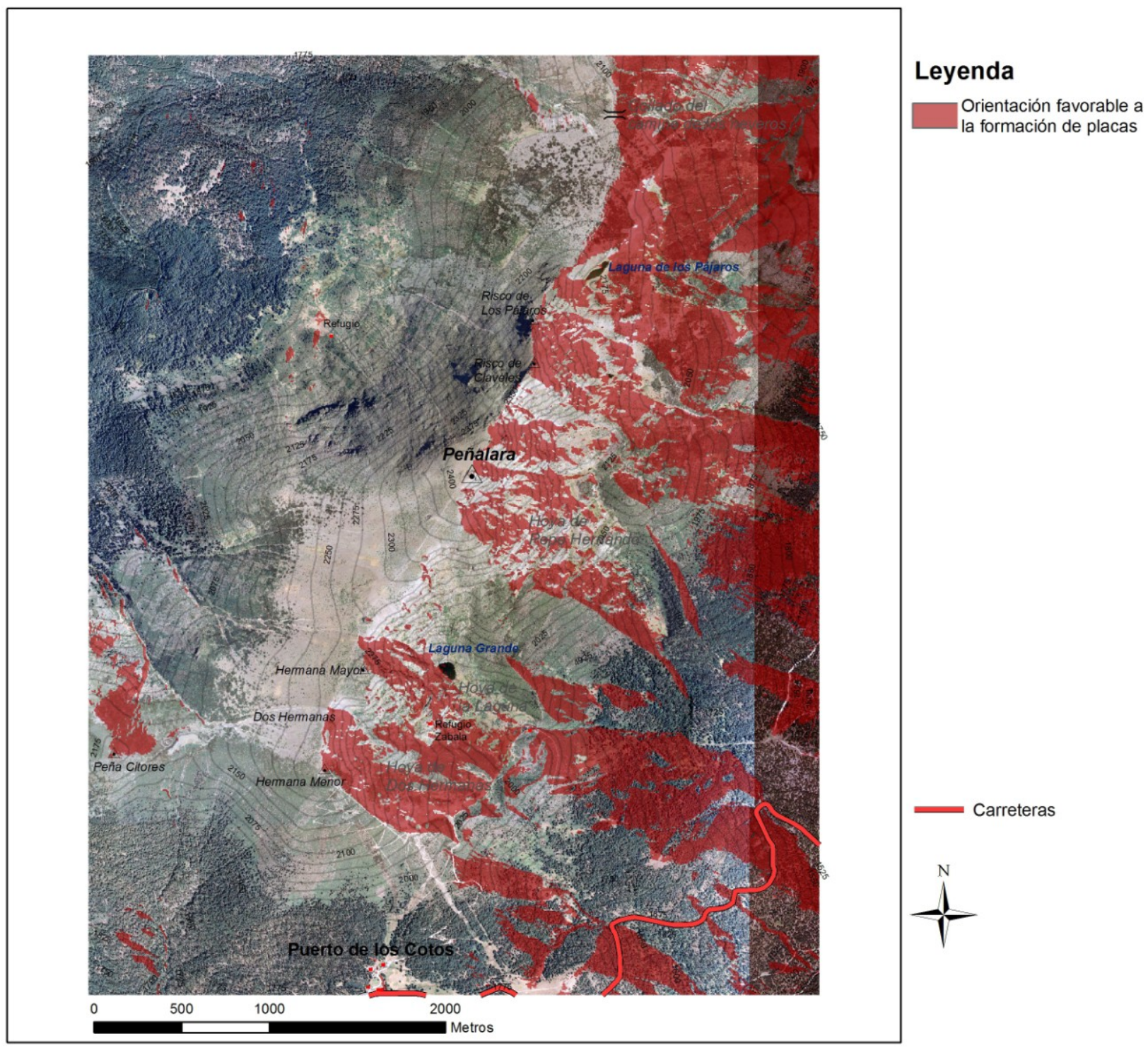

Figura a.6: Laderas con orientación este, favorable a la formación de placas en el Macizo de Peñalara. Datos: PNOA (IGN). Elaboración propia. 


\section{ÁREAS CON INSOLACIÓN MÁXIMA Y MÍNIMA}

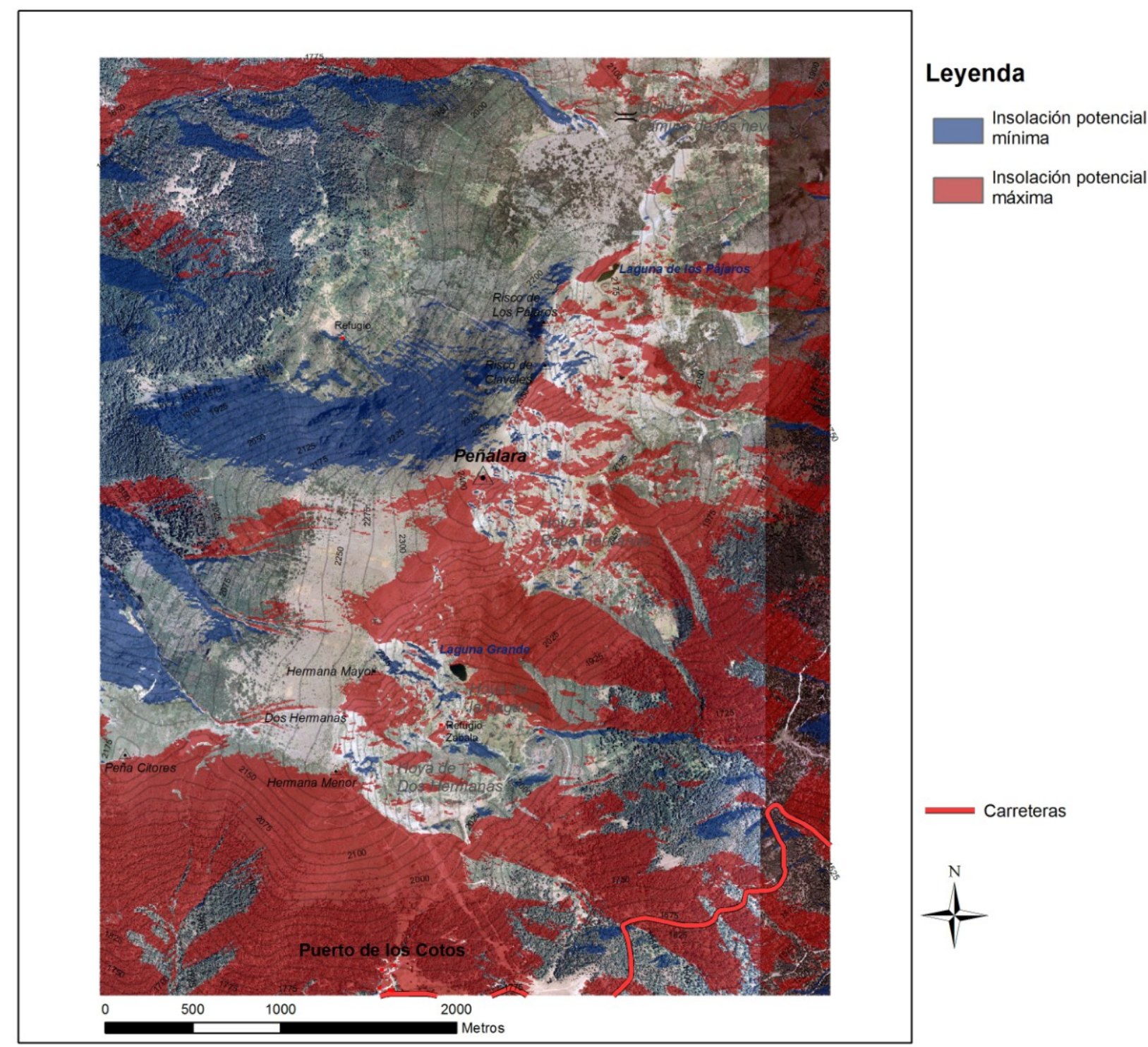

Figura a.7: Áreas con insolación máxima y mínima en el Macizo de Peñalara.

Datos: PNOA (IGN). Elaboración propia. 


\section{ANEXO II. INDICE DE FIGURAS.}

Figura 1: $\quad$ Mapa de situación del Macizo de Peñalara.

Figura 2: $\quad$ Acumulación de la nieve a sotavento con formación de cornisas y placas de viento.

Figura 3: Datos de precipitación y temperatura máxima y mínima del observatorio del Puerto de Navacerrada (1.888 $\mathrm{m}$ de altitud) de AEMET.

Figura 4: Datos del observatorio del Puerto de Navacerrada (1.888 $\mathrm{m}$ de altitud) de AEMET.

Figura 5: $\quad$ Ejemplos de cornisas.

Figura 6: Histograma de la insolación potencial de noviembre a mayo en el Macizo de Peñalara.

Figura 7: $\quad$ Tamaño de los aludes según la EAWS (European Avalanche Warning Services).

Figura 8: $\quad$ Variables utilizadas en la elaboración de la cartografía de zonas favorables al desencadenamiento de aludes.

Figura 9: $\quad$ Escala del mapa de áreas de desencadenamiento de aludes de placa.

Figura 10: Variables utilizadas en la elaboración de la cartografía de zonas favorables al desencadenamiento de aludes.

Figura 11: Escala de Clasificación del Terreno favorable al desencadenamiento de avalanchas (Avalanche Terrain Exposure Scale, ATES).

Figura 12: $\quad$ Mapa de aludes observados.

Figura 13: $\quad$ Perfil de los aludes observados en el Macizo de Peñalara.

Figura 14: Características y dimensiones de los aludes observados en el Macizo de Peñalara.

Figura 15: Mapa de áreas favorables al desencadenamiento de aludes de placa en el Macizo de Peñalara.

Figura 16: Ejemplo de alud de placa.

Figura 17: Mapa de áreas favorables al desencadenamiento de aludes de fusión en el Macizo de Peñalara.

Figura 18: Ejemplo de alud de fusión.

Figura 19: Mapa de áreas favorables al desencadenamiento de aludes de nieve reciente en el Macizo de Peñalara.

Figura 20: Ejemplo de alud de nieve polvo por rotura de placa friable sobre el refugio de Zabala.

Figura 21: Mapa de áreas favorables al desencadenamiento de aludes en el Macizo de Peñalara. 
Figura 22: $\quad$ Mapa de áreas favorables al desencadenamiento de aludes en el Macizo de Peñalara según criterios ATES.

Figura 23: Mapa de áreas favorables al desencadenamiento de aludes en el Macizo de Peñalara según los criterios ATES y según los establecidos en el trabajo.

Figura a.1: Mapa de áreas con bosques densos en el Macizo de Peñalara.

Figura a.2: $\quad$ Mapa de áreas de acumulación de nieve en el Macizo de Peñalara.

Figura a.3: $\quad$ Mapa de áreas con pendiente superior a $25^{\circ}$ en el Macizo de Peñalara.

Figura a.4: Mapa de áreas con pendiente superior a $30^{\circ}$ en el Macizo de Peñalara.

Figura a.5: Mapa de áreas con pendiente superior a $45^{\circ}$ en el Macizo de Peñalara.

Figura a.6: Mapa de áreas con orientación este en l Macizo de Peñalara.

Figura a.7: $\quad$ Mapa de áreas con insolación mínima y máxima en el Macizo de Peñalara. 